\title{
Cloud-Atmospheric Boundary Layer-Surface Interactions on the Greenland Ice Sheet during the July 2012 Extreme Melt Event ${ }^{\circ}$
}

\author{
Amy Solomon, Matthew D. Shupe, And Nathaniel B. Miller \\ Cooperative Institute for Research in Environmental Science, University of Colorado Boulder, and NOAA/Earth \\ System Research Laboratory Physical Sciences Division, Boulder, Colorado
}

(Manuscript received 20 January 2016, in final form 30 January 2017)

\begin{abstract}
Regional model simulations of the 10-13 July 2012 extreme melt event over the Greenland Ice Sheet (GIS) are used to investigate how low-level liquid-bearing clouds impact surface energy fluxes, and therefore the energy available for melt. A sensitivity study in which the radiation code is modified so that cloud liquid and ice do not emit, absorb, or reflect radiation is used to identify cloud impacts beyond the cloud radiative effect. It is found that Arctic mixed-phase stratocumuli are not produced in the sensitivity experiment, highlighting that cloud radiative fluxes are required to maintain the clouds. A number of feedbacks are found that damp the warming effect of the clouds. Thin mixed-phase clouds increase the downward longwave fluxes by $100 \mathrm{~W} \mathrm{~m}^{-2}$, but upward daytime surface longwave fluxes increase by $20 \mathrm{~W} \mathrm{~m}^{-2}\left(60 \mathrm{~W} \mathrm{~m}^{-2}\right.$ at night $)$ and net shortwave fluxes decrease by $40 \mathrm{~W} \mathrm{~m}^{-2}$ (partially due to a 0.05 increase in surface albedo), leaving only $40 \mathrm{~W} \mathrm{~m}^{-2}$ available for melt. This $40 \mathrm{~W} \mathrm{~m}^{-2}$ is distributed between the turbulent and conductive ground fluxes, so it is only at times of weak turbulent fluxes (i.e., at night or during melt) that this energy goes into the conductive ground flux, providing energy for melt. From these results it is concluded that it is the integrated impact of the clouds over the diurnal cycle (the preconditioning of the snowpack by the clouds at night) that made melt possible during this 3-day period. These findings are extended to understand the pattern of melt observed over the GIS.
\end{abstract}

\section{Introduction and motivation}

The fate of the Greenland Ice Sheet (GIS) in a warming world will impact climate globally. For example, if the entire GIS melts, sea level is predicted to rise by up to $7 \mathrm{~m}$ (IPCC 2013), thereby increasing flooding of coastal land and causing saltwater intrusion into groundwater (Nicholls and Cazenave 2010; Fettweis et al. 2013; IPCC 2013). In addition, an increase in freshwater flux due to increased melt will impact ocean circulations, potentially weakening the Atlantic meridional overturning circulation (MaierReimer and Mikolajewicz 1989; Stouffer et al. 2006; Rahmstorf et al. 2015), resulting in global and regional impacts, such as additional sea level rise in the northeast coast of the United States (Yin et al. 2009).

Supplemental information related to this paper is available at the Journals Online website: http://dx.doi.org/10.1175/ JCLI-D-16-0071.s1.

Corresponding author e-mail: Amy Solomon, amy.solomon@ noaa.gov
Observations of the late twentieth century indicate that summer melt has accelerated on the GIS, most notably along coastal regions (Vaughan et al. 2013). From 2003 to 2010, a net mass loss from the GIS and its peripheral glaciers (Zwally et al. 2002) contributed $\sim 0.61 \mathrm{~mm} \mathrm{yr}^{-1}$ of sea level rise, $40 \%$ of the total contribution from melting ice globally (Jacob et al. 2012). Over the past two decades there has been a trend toward increasing GIS melt and mass loss (Fettweis et al. 2013), leading to a number of record melt years (Tedesco et al. 2013) and providing increasing contributions to sea level rise (Rignot et al. 2011). This observed increase in melt is hypothesized to produce an irreversible decline of the GIS due to a surface-elevation feedback that operates when a decrease of the elevation of the ice sheet induces a decreased surface mass balance, generally through increased melting (Ridley et al. 2010).

In this study we focus on the recent extreme melt event of July 2012, where over $90 \%$ of the GIS surface experienced melt (Nghiem et al. 2012). At this time melt even occurred at Summit Station (hereafter Summit) at $3216 \mathrm{~m}$ above sea level, which previously experienced 
melt 126 years before in 1889 . While not directly attributable to anthropogenic forcing (Fettweis et al. 2013), this event demonstrated that increased transport of warm moist air aloft from the North Atlantic into the Arctic can accelerate melting of the GIS (Hanna et al. 2014; Neff et al. 2014). At the top of the ice sheet this melt was shown to be enhanced by the presence of thin liquid-bearing clouds (Bennartz et al. 2013). Liquidbearing clouds at temperatures below the freezing point, which are often mixed phase (i.e., containing both cloud ice and liquid), are challenging to model due to the inherent instability of liquid in the presence of ice (Wegener 1911; Bergeron 1935; Findeisen 1938; Turner et al. 2007a; Morrison et al. 2012).

Bennartz et al. (2013) used a surface energy balance model to demonstrate that melting would not have occurred at Summit without the warming effect of low-level thin mixed-phase clouds, which were optically thick enough to enhance downwelling longwave radiation but thin enough to allow downwelling solar radiation to reach the surface. Mixed-phase clouds are common at Summit (Shupe et al. 2013) and play a critical role in the Arctic surface energy balance (Shupe and Intrieri 2004), radiatively warming the highly reflective surface at Summit year-round (Miller et al. 2015).

The energy balance model used in Bennartz et al. (2013) was very powerful in demonstrating that surface melt would not have occurred at Summit in July 2012 without the radiative impact of thin low-level stratocumulus clouds. However, more sophisticated models are needed to investigate coupled feedbacks that exist in this system, such as the response of near-surface ice temperatures to lowlevel cloud formation or changes in albedo due to surface melt. In this study we use limited-area model simulations of the July 2012 extreme melt event to go beyond cloud radiative effect estimates and to investigate the coupled feedbacks related to these low-level clouds that influence surface energy fluxes, and therefore the energy available for melt, at Summit and across the GIS.

\section{Model setup and experiment design}

The Weather Research Forecast (WRF) Model V3.6.1 (Skamarock et al. 2008) is used for this study with a $3000 \mathrm{~km} \times 3000 \mathrm{~km}$ horizontal domain (Fig. 1) with grid spacing of $24 \mathrm{~km}$ and $129(x)$ by $129(y)$ by $80(z)$ grid points. The boundary layer is well resolved in the vertical by including eight levels in the lowest $1 \mathrm{~km}$. The model is forced with lateral and surface boundary conditions from the European Centre for Medium-Range Weather Forecasts (ECMWF) 6-hourly, T255 ERAInterim dataset. The model is spun up by integrating from 0000 UTC 8 July to 0000 UTC 10 July 2012.

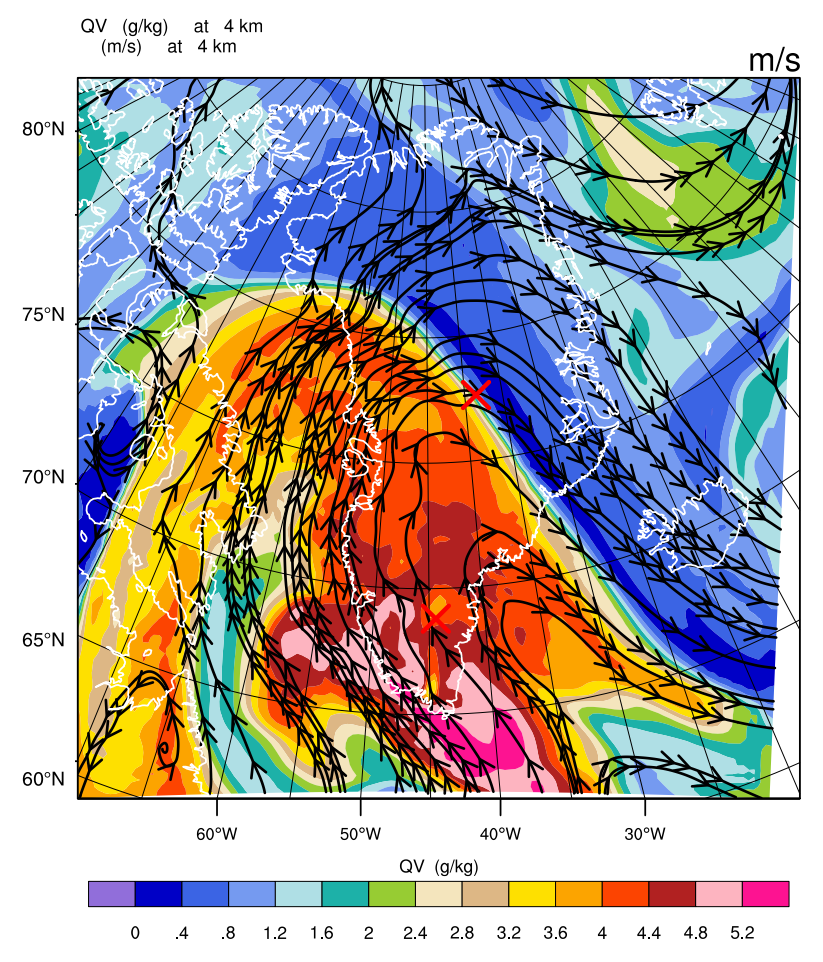

FIG. 1. Water vapor mixing ratio (QV) and streamlines at $4 \mathrm{~km}$ (the approximate height of the stratocumulus cloud layer at Summit between 10 and 12 Jul 2012) on 0200 UTC 10 Jul 2012 when the moist air mass reaches Summit from WRF control simulation initialized 0000 UTC 8 Jul 2012 (in units of $\mathrm{g} \mathrm{kg}^{-1}$ and $\mathrm{m} \mathrm{s}^{-1}$, respectively). Red crosses mark the location of Summit and South Dome. White lines indicate coastlines.

The WRF configuration uses the National Center for Atmospheric Research Community Atmospheric Model (CAM) longwave and shortwave radiation package, where the radiation code allows for interactions with resolved clouds and cloud fractions (Collins et al. 2004). The CAM radiation package includes a diagnostic for clear-sky radiative fluxes calculated using the broadband absorptivity/emissivity method. The term "clear-sky" throughout the paper refers to clear-sky radiation fluxes calculated diagnostically. Boundary layer mixing is parameterized with the Grenier-Bretherton-McCaa scheme, which uses a 1.5-order turbulent closure model with an entrainment closure at the boundary layer top and has been tested for cloud-topped boundary layers (Grenier and Bretherton 2001; Bretherton et al. 2004). The surface layer is parameterized with the revised fifth-generation Penn State/NCAR Mesoscale Model surface layer scheme, which includes modifications to provide more suitable similarity functions to simulate the surface layer evolution under strong stable/unstable conditions (Jiménez et al. 2012).

The Community Land Model Version 4 (CLM4; Oleson et al. 2010; Lawrence et al. 2011) is used to simulate the ice sheet and surrounding land surfaces. Of 
specific interest to this study, CLM4 includes a fivelayer snowpack/firn model, which allows for percolation and refreezing, and the SNICAR (Snow and Ice Aerosol Radiation) model, which is used to calculate snow albedo and vertically resolved snowpack heating (Flanner and Zender 2005, 2006). A snow aging routine is used to calculate the effective snow grain size. This grain size is dependent upon dry snow metamorphism, liquid water-induced metamorphism, refreezing of liquid water, and addition of freshly fallen snow. SNICAR also incorporates a two-stream radiative transfer solution based on Toon et al. (1989). Snow albedo and the vertical absorption profile depend on solar zenith angle, the albedo of the substrate underlying snow, mass concentrations of atmospheric-deposited aerosols (black carbon, mineral dust, and organic carbon), and the ice effective grain size. Solar fluxes are computed in five spectral bands (four near-infrared bands and one visible band), and solar absorption is calculated in all snow layer.

Microphysics is simulated with the Morrison twomoment scheme, which includes prognostic equations for mixing ratio and number concentration for cloud droplets, cloud ice, rain, snow, and graupel/hail. Ice is initiated by contact and immersion freezing for temperatures greater than $-40^{\circ} \mathrm{C}$ and by homogeneous nucleation for temperatures less than $-40^{\circ} \mathrm{C}$. Cloud droplets are activated in regions of low cloud water content using resolved and subgrid vertical motion (Morrison and Pinto 2005) and a lognormal aerosol size distribution to derive cloud condensation nuclei spectra following Abdul-Razzak and Ghan (2000). The lognormal dry aerosol size distribution is given by

$$
\frac{d N}{d \ln r}=\frac{N_{t}}{\sqrt{2 \pi} \ln \sigma} \exp \left[\frac{\ln ^{2}\left(r / r_{m}\right)}{2 \ln ^{2} \sigma}\right],
$$

where $N$ is the number concentration of aerosols and $r$ is the particle radius. The parameters $N_{t}, r_{m}$, and $\sigma$ are total number concentration, geometric mean radius and standard deviation of each particle mode [estimated from Strellis (2013)] and are given the values $30 \mathrm{~cm}^{-3}$, $0.188 \mu \mathrm{m}$, and 1.4 , respectively. Aerosol composition is assumed to be $30 \%$ insoluble by volume, with the remaining soluble component consisting of ammonium bisulfate. Morrison et al. (2009) and Morrison and Pinto (2005) provide details of the parameterizations used in this microphysical scheme.

Solutions from two simulations are presented in this paper. The first simulation is the control simulation described above. The second simulation is a sensitivity study that uses a radiation code that has been modified to remove the radiative response to cloud liquid and ice in a limited region around Summit. Results from the control simulation are presented in section 5a. The sensitivity study is referred to as the "radiation denial experiment" and is presented in section $5 \mathrm{~b}$.

\section{Large-scale conditions observed during July 2012}

A rare melt event, unprecedented in the satellite record, was observed over the GIS in July 2012 (Nghiem et al. 2012). The surface temperatures at Summit first rose to the melting point on 11 July. As demonstrated in Neff et al. (2014), there were three main factors that contributed to this melt event: 1) the eastward advection of a warm air mass from central North America, which was experiencing a heat wave, 2) advection of this air mass over the Atlantic Ocean where it was moistened due to fluxes of water vapor from the ocean, and 3) a blocking high pressure feature associated with a negative phase of the North Atlantic Oscillation (NAO) that caused this warm, moist air mass to be advected northward along the west coast, then up over the top of the GIS (Hanna et al. 2014).

Regional WRF Model diagnostic studies were completed that used passive tracers to identify the source of air masses that led to the mixed-phase stratocumulus that formed over Summit during the melt event on 11 July. It was found that $\sim 95 \%$ of the air mass that formed these clouds was advected into the domain from the southern boundary $\left(\sim 58^{\circ} \mathrm{N}\right)$ above the boundary layer. This result is consistent with the model study of Hanna et al. (2013), which showed little sensitivity of the free atmosphere over the GIS to sea surface temperature changes due to katabatic winds, which often flow down the ice sheet and limit the influence of boundary layer air. Therefore, we conclude from these studies that the air masses that produced the extreme melt event at the top of the ice sheet were of remote origin, consistent with the studies of Neff et al. (2014) and Hanna et al. (2014); however, this does not preclude the impact of local forcing on the large-scale circulation, as suggested by Overland et al. (2012).

The tracer studies also showed that the air mass where mixed-phase clouds formed at Summit on 11 July originated at the southern model domain boundary on 8 July. The air mass over Summit on 11 July took different paths depending on the original height at the boundary and the final height above Summit. Air masses that originated at $\sim 3 \mathrm{~km}$ along the southern boundary at 0000 UTC 8 Jul 2012 were advected along the west coast of the GIS and then lifted up over the ice sheet to Summit by the anticyclonic circulation arriving at $3.6 \mathrm{~km}$ while air masses that originated higher than $\sim 4 \mathrm{~km}$ were advected northward over the top of the ice sheet with little change in height to Summit. These air masses experienced very different modifications 
along these two pathways, with air advected northward over the top of the ice sheet having very little change in water vapor amount and potential temperature, in contrast to air lifted up over the ice sheet that was warmed by condensation and dried by the formation of cloud ice.

\section{Validation datasets}

Observations to validate the model simulations at Summit are taken from the Integrated Characterization of Energy, Clouds, Atmospheric State, and Precipitation at Summit (ICECAPS) campaign (Shupe et al. 2013), which has been measuring atmospheric, cloud, and precipitation properties at Summit since May 2010, broadband radiative flux measurements maintained by the Swiss Federal Institute of Technology (ETH) Zürich, and sensible heat flux measurements made by Dr. David Noone at Summit.

Observations of surface upwelling and downwelling longwave and shortwave radiation are made at approximately $2 \mathrm{~m}$ above the surface. The upwelling and downwelling longwave fluxes (LW $\uparrow$ and $\mathrm{LW} \downarrow$ ) are measured by a pair of Kipp and Zonen CG4 pyrgeometers, while the upwelling and downwelling solar irradiances ( $\mathrm{SW} \uparrow$ and $\mathrm{SW} \downarrow$ ) are measured by a pair of Kipp and Zonen CM22 pyranometers. Daily checks of the radiometer domes were performed by an on-site field technician and external ventilation is used to limit riming and frosting, which can occur frequently at Summit. Processing of this radiometer data is described in detail by Miller et al. (2015). The surface temperature is estimated from upwelling longwave measurements using the greybody approximation with surface emissivity, $\varepsilon$, set equal to 0.985 ( $\sigma=$ Stefan-Boltzmann constant):

$$
T_{\text {surf }}=\{[\mathrm{LW} \uparrow-(1-\varepsilon) \mathrm{LW} \downarrow] /(\varepsilon \sigma)\}^{0.25} .
$$

Sensible heat fluxes are calculated via the eddy correlation method using a three-dimensional Metek USA1 sonic anemometer, which measures wind speed and temperature at a $20-\mathrm{Hz}$ sampling rate. Strict quality control procedures where implemented to account for nonstationary conditions and erroneous values due to environmental factors. The cloud liquid water path (LWP) is retrieved from four channels $(23.84,31.40,90.0$, and $150.0 \mathrm{GHz})$ measured by a pair of microwave radiometers (Turner et al. 2007b). The cloud ice water path (IWP) is derived from $35-\mathrm{GHz}$ cloud radar measurements (Shupe et al. 2015).

\section{Results}

\section{a. Control simulation}

Validation of the control simulation at Summit is focused on surface energy fluxes (Fig. 2), surface temperatures, and cloud LWP and IWP (Fig. 3). All fluxes shown are positive

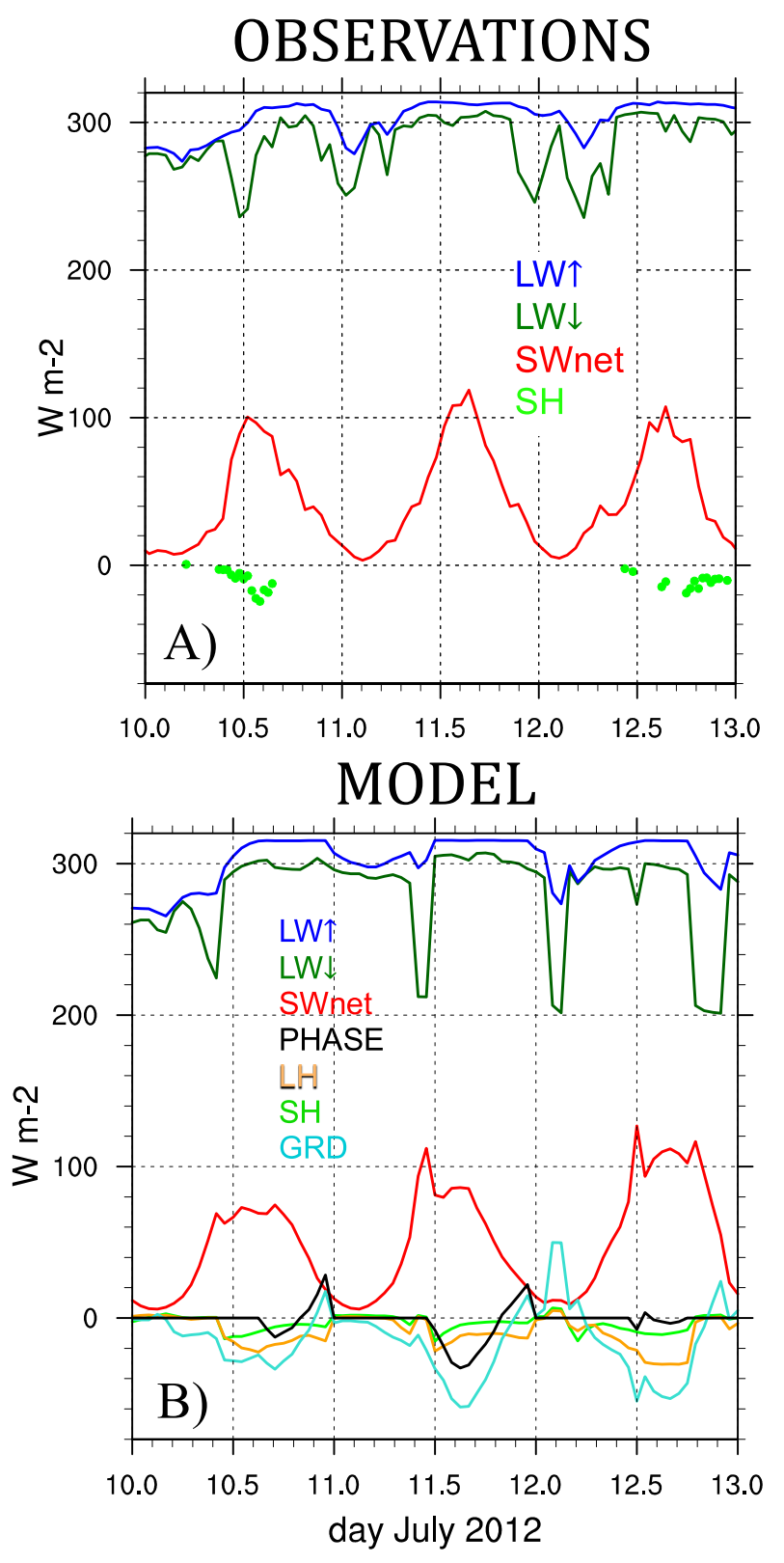

FIG. 2. Validation of surface energy fluxes at Summit 10-13 Jul 2012 (in $\mathrm{W} \mathrm{m}^{-2}$ ). (a) Observed surface radiative and sensible heat fluxes. (b) Control model simulation surface fluxes. [LW $\uparrow=$ upward surface longwave fluxes (blue), $\mathrm{LW} \downarrow=$ downward surface longwave fluxes (dark green), SWnet = net surface shortwave fluxes (red), $\mathrm{LH}=$ latent heat fluxes (orange), $\mathrm{SH}=$ sensible heat fluxes (light green), GRD = conductive ground fluxes (aqua), PHASE = energy flux due to phase change (purple), NET = net surface energy flux (black).]

toward the surface. In CLM4, the surface energy budget can be written as

$\mathrm{LW} \uparrow-\mathrm{LW} \downarrow+\mathrm{SWnet}+\mathrm{GRD}+\mathrm{SH}+\mathrm{LH}=0$,

where $\mathrm{SWnet}=\mathrm{SW} \uparrow-\mathrm{SW} \downarrow$, GRD is the conductive ground flux, $\mathrm{SH}$ is the sensible heat flux, and LH is the 


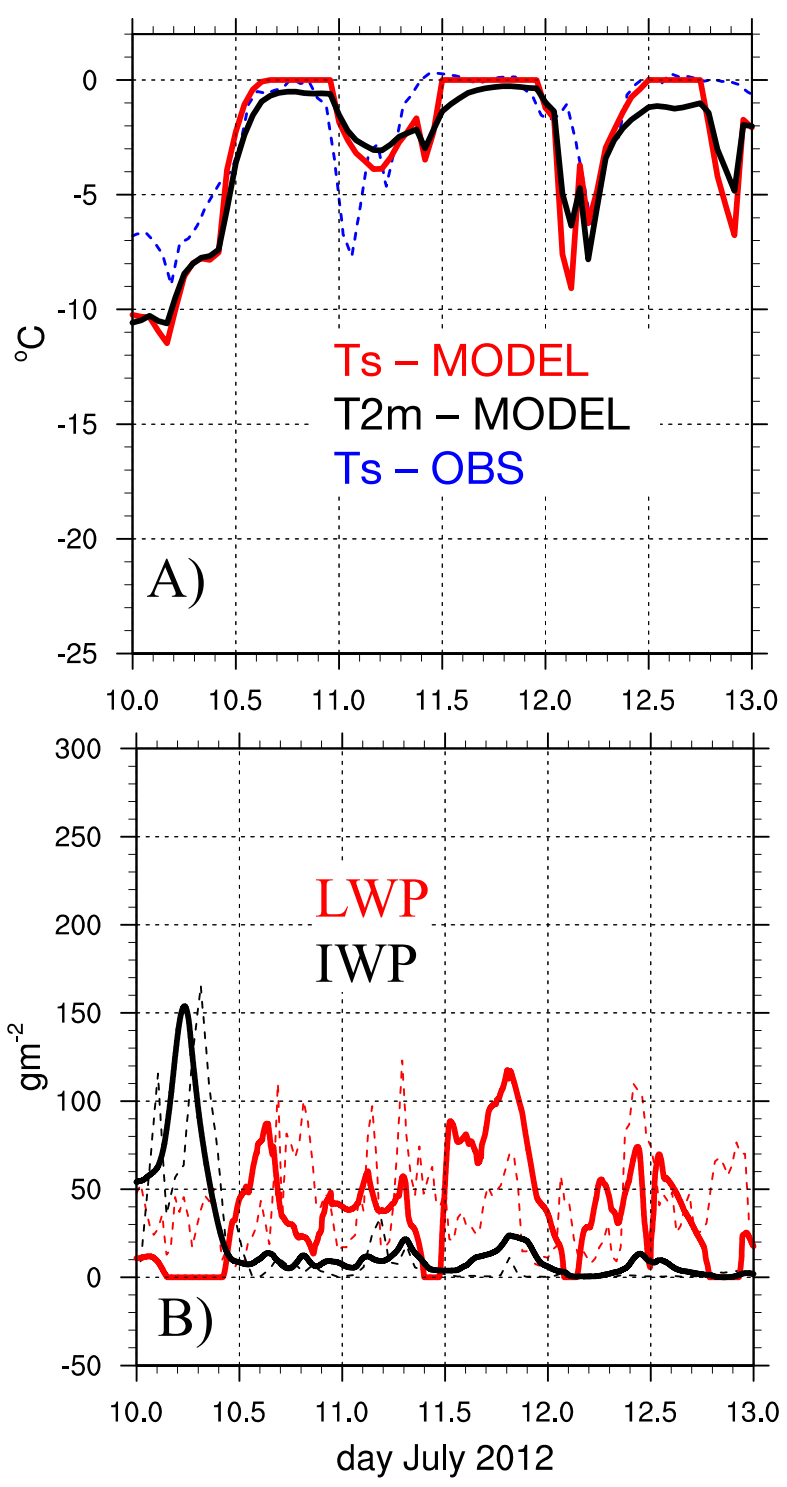

FIG. 3. 30-min time series at Summit on 10-13 Jul 2012. (a) Modeled surface temperature (Ts) and 2-m temperature (T2m) (red and black lines). Observed surface temperature estimated is from $\mathrm{LW} \uparrow$ (dashed blue line), in units of ${ }^{\circ} \mathrm{C}$. (b) Liquid water path (LWP; red) and ice water path (IWP; black) from the control simulation (solid lines) and retrievals (dashed lines), in units of $\mathrm{g} \mathrm{m}^{-2}$.

latent heat flux. The energy flux that goes into phase change (PHASE, hereinafter) is calculated within the snowpack model.

Figure 2 compares energy fluxes from the control simulation with the measurements described in section 4 from 0000 UTC 10 July to 0000 UTC 13 July. An upward longwave radiative flux of approximately $311 \mathrm{~W} \mathrm{~m}^{-2}$ is an indication that the surface temperature is at $0^{\circ} \mathrm{C}$ (see Fig. 3a). Both the model and measurements show that surface temperatures were at $0^{\circ} \mathrm{C}$ for extended periods on all three days. Net longwave flux is less than $-10 \mathrm{~W} \mathrm{~m}^{-2}$ in magnitude for LWP greater than approximately $20 \mathrm{~g} \mathrm{~m}^{-2}$ or IWP greater than approximately $100 \mathrm{~g} \mathrm{~m}^{-2}$, regardless of the amount of incoming solar radiation, in both the model and observations. Downward longwave flux in the model can be as low as $200 \mathrm{~W} \mathrm{~m}^{-2}$, while observations show downward longwave flux larger than $230 \mathrm{~W} \mathrm{~m}^{-2}$ over the 3-day period, indicating that the model produces brief periods of clear sky while the observations indicate more persistent thin liquid-bearing clouds (see Fig. 3b).

The model produces turbulent fluxes and conductive ground fluxes that together reduce the net surface energy flux by $55-80 \mathrm{~W} \mathrm{~m}^{-2}$ at peak incoming solar radiation and increase (decrease) the surface energy flux by 60 (20) $\mathrm{W} \mathrm{m}^{-2}$ at night when cloud-free (cloudy). Melt of surface snow produces a reduction in the ground flux by up to $20 \mathrm{~W} \mathrm{~m}^{-2}$ on 10 July and $30 \mathrm{~W} \mathrm{~m}^{-2}$ on 11 July. There is a close comparison between observed and modeled sensible heat fluxes when observations are available, suggesting that the surface layer parameterizations are adequately simulating the turbulent fluxes (Fig. 2).

Figure 3 shows the comparison between modeled and observed surface temperature (Fig. 3a) and cloud LWP and IWP (Fig. 3b). The rapid increase in temperature on $10 \mathrm{July}$ and the periods of $0^{\circ} \mathrm{C}$ surface temperature are realistically simulated by the model. The modeled 2-m air temperatures are also consistent with the measurements except around 1500 UTC 11 July when the measurements indicate that air temperatures are greater than $0^{\circ} \mathrm{C}$ and the modeled temperatures are less than $0^{\circ} \mathrm{C}$ (results not shown). In addition, the model produces liquid-bearing clouds with similar LWP magnitude and variability relative to the measurements, and a very limited amount of cloud ice after about 1200 UTC 10 July (Fig. 3b). Figure 4 shows the surface albedo at Summit in the control simulation compared to the measurements. The SNICAR model realistically simulates the slow decrease in albedo from 0.88 to 0.82 over the 3-day period.

Figure 5 shows the modeled surface cloud radiative effect (estimated as the all-sky surface radiative fluxes minus the clear-sky surface radiative fluxes) compared to the absolute value of the surface flux due to melt and the difference of these two components. It is clearly seen that cloud radiative effect is always positive, even during maximum incoming solar radiation. This is an interesting aspect of cloud radiative effect at Summit (Miller et al. 2015), which is shown below to be sensitive to small changes in albedo. The blue curve shows the sum of the flux due to melt and the net cloud radiative effect. If the blue curve is negative this indicates that 


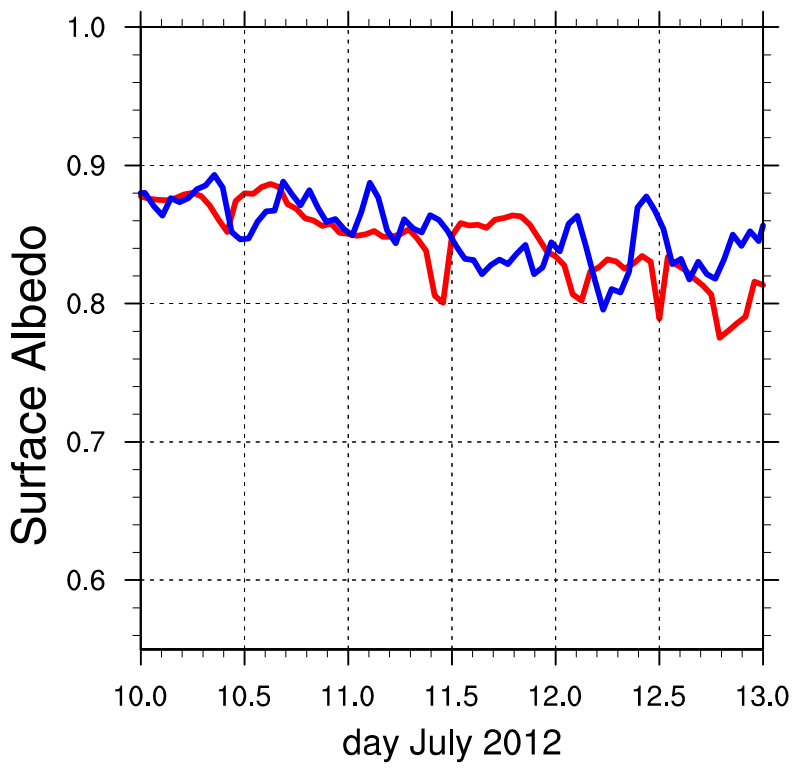

FIG. 4. Surface albedo at Summit on 10-13 Jul 2012. Hourly from the control simulation (red) from measurements (blue).

clear-sky radiation is smaller than the sum of turbulent and conductive fluxes and therefore the warming effect of clouds is needed to produce melt. If the blue curve is positive this means that clear-sky radiation is strong enough to produce melt without clouds. There is a short period on 11 July when the model results indicate that the solar radiation is strong enough to produce melt without clouds; however, the extensive melt over the 3-day period is primarily made possible by the presence of liquid-bearing clouds, in general agreement with Bennartz et al. (2013).

Plotting the magnitude of the energy flux due to melt in the top snow layer plus cloud radiative fluxes (or alternatively, the balance between warming due to clearsky radiative fluxes and the cooling due to turbulent fluxes plus residual conductive fluxes in the top snow layer, i.e., conductive fluxes that produce a change in snow temperature) across the full GIS indicates the regions where thin, liquid-bearing stratocumulus clouds are needed to produce melt versus those where melt would have occurred even without the warming effect of clouds (Fig. 6a). Averaged over 1200-2000 UTC 11 July when prolonged melt was observed, clouds are generally needed for melt at elevations above $2 \mathrm{~km}$ poleward of Summit. Interestingly, melt does not occur at all above $2 \mathrm{~km}$ equatorward of Summit at this time. This result is discussed in more detail in section $5 \mathrm{~d}$.

\section{b. Radiation denial experiment}

In this study we are interested in identifying the impacts of mixed-phase stratocumulus beyond their direct

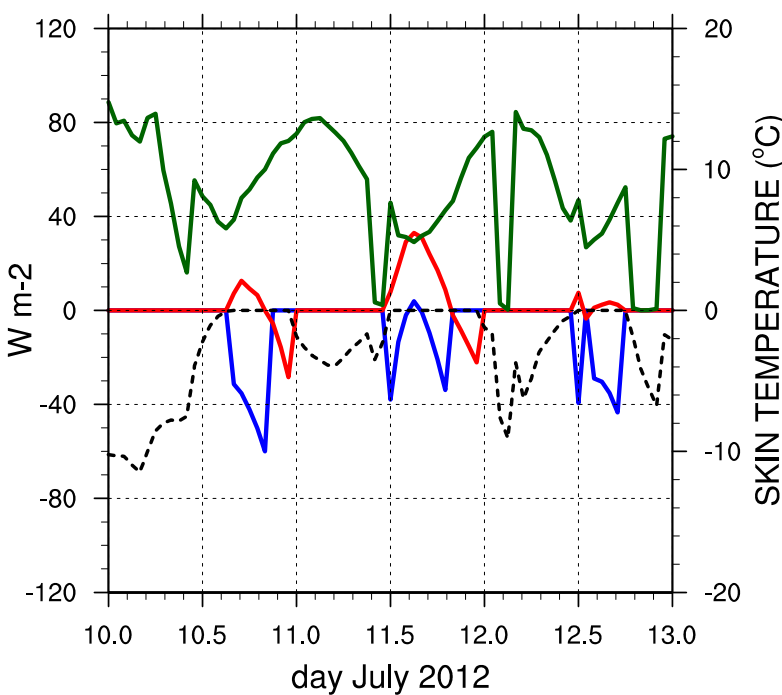

FIG. 5. Surface energy fluxes at Summit 10-13 Jul 2012 from control simulation, in units of $\mathrm{W} \mathrm{m}^{-2}$, showing net cloud radiative effect (green) and fluxes due to melt (surface flux due to phase change times minus one; red), and fluxes due to melt plus net cloud radiative fluxes (blue). Surface temperature indicated with a dashed black line. When blue line is negative this indicates clouds are required to produce melt.

cloud radiative effect, specifically the impact of lowlevel stratocumulus clouds on the atmospheric structure, other surface flux terms, and the temperature of the snow on the ice sheet. To examine these processes a sensitivity study was performed in which the radiation code was modified so that cloud liquid and ice do not emit, absorb, or reflect radiation. In other words, a clear-sky radiation calculation was performed at every time step. The radiation code was only modified in the central GIS in the region where clouds are generally needed to produce melt during this period (outlined in red in Fig. 6) so that the characteristics and trajectories of the air masses advected to the region near Summit are not modified upstream. In addition, the modified radiation scheme starts at 600010 July when the warm moist air mass reaches Summit to focus on cloud formation during 10-13 July.

Considering the impact of these clouds on surface melt over the ice sheet, positive values in Figs. $6 \mathrm{a}$ and $6 \mathrm{~b}$ indicate where the instantaneous radiative effects of clouds are needed for the surface to reach the melting point of snow. On the other hand, negative values indicate where clear-sky radiation exceeds turbulent and conductive fluxes and clouds are not needed to produce melt. In general, the results from the sensitivity study are consistent with the control simulation, with regions outside the red box in Fig. 6 showing generally similar patterns. However, inside the box there is no surface melt in the sensitivity study, indicating that clouds are needed in this region to produce melt. 
A) With Cloud Radiation

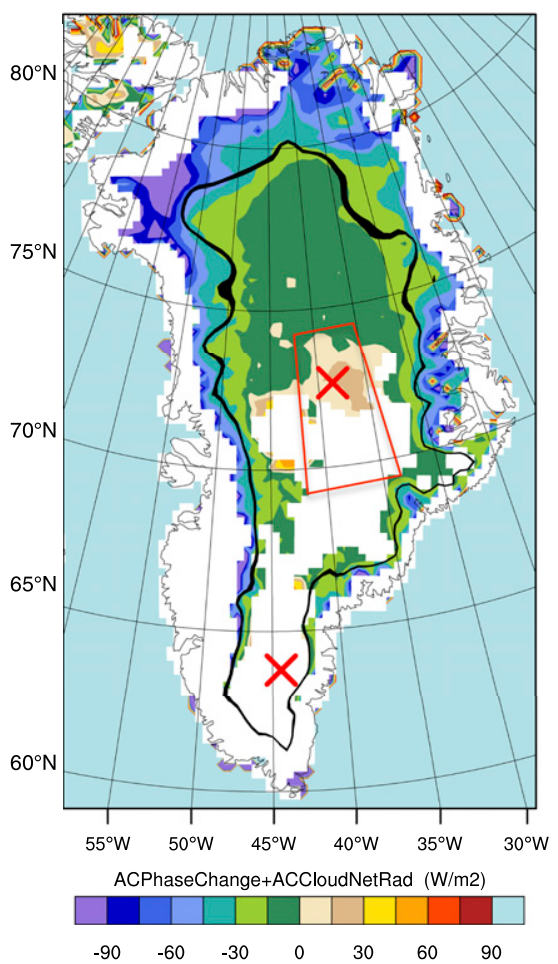

B) Without Cloud Radiation

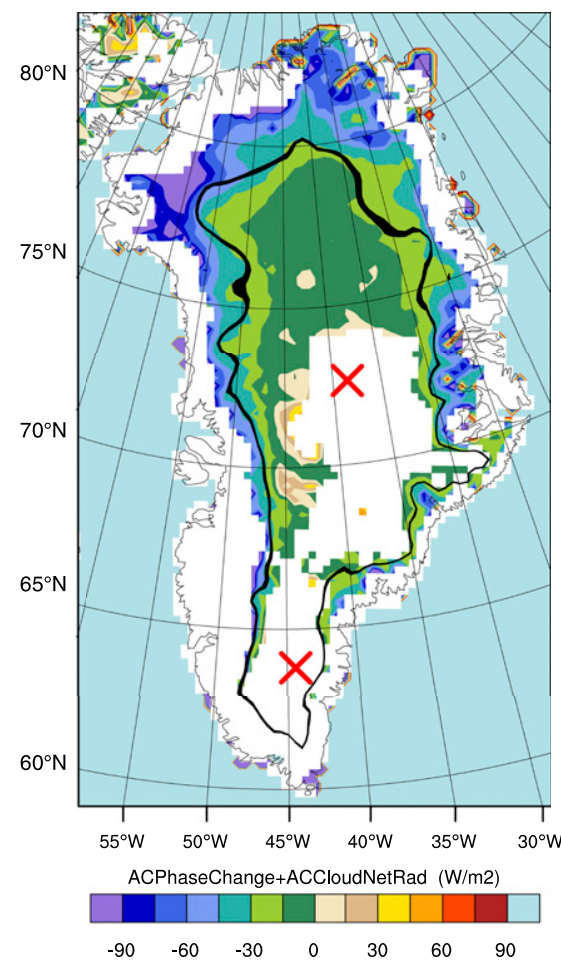

FIG. 6. Surface energy flux that clouds need to produce for melt to occur (phase change plus

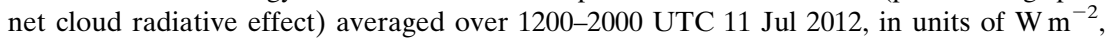
shown (a) with and (b) without cloud radiation. Positive values indicate that cloud radiative fluxes are needed to produce melt. Negative values indicate melt would have occurred without clouds. White shading means melt did not occur at this time. Red outline shows region where radiation code does not see cloud liquid and ice. Red crosses mark Summit and South Dome. Thick black contour indicates terrain height of $2 \mathrm{~km}$.

Figure 7 shows the impact of cloud radiative processes on the formation and maintenance of stratocumulus clouds. In the control run, mixed-phase stratocumulus form around 1200 UTC 10 July at $0.7-1.0 \mathrm{~km}$ above the surface and persist until the end of 12 July. Mixed-phase stratocumuli are completely absent in the sensitivity study. Cloud liquid forms at night when the near-surface air becomes saturated with respect to water, but this is simply due to near-surface atmospheric radiative cooling since there is no radiative response to the presence of cloud liquid. This sensitivity study clearly shows that the mixed-phase stratocumuli are self-maintained by the cloud-top radiative cooling that drives turbulence, which maintains the production of cloud liquid.

The impact of these cloud processes on the atmospheric temperature structure is shown in Fig. 8. It is seen that, with clouds present, longwave cooling reduces the temperature by $3^{\circ}-5^{\circ} \mathrm{C}$ at cloud top and downward longwave fluxes warm the surface by $3^{\circ}-4^{\circ} \mathrm{C}$. This reduction in stratification from cloud top to the surface is a result of the homogenization of the cloud-topped boundary layer by cloud-driven turbulent mixing and radiative processes.

The net warming of the surface by the clouds also has a temporally integrated impact on the snowpack that feeds back to the amount of energy available for melt (Fig. 9). While the subsurface snow temperatures increase during the day by approximately the same amount as they decrease during the night when clouds are not present, the presence of clouds causes subsurface temperatures to continually increase over the 3-day period (down to at least $50 \mathrm{~cm}$ ), primarily due to warming at night and the erosion of the surface temperature inversion. This continual warming of subsurface snow layers, especially near the surface, results in smaller conductive heat fluxes, which allows for additional surface fluxes to more easily produce melt (a positive feedback).

The net impact of the clouds (control minus radiation denial simulation) at Summit on the surface energy budget is seen in Fig. 10. Clouds increase the surface albedo by 0.04 0.06 at times of peak incoming solar radiation (Fig. 10a). For downwelling surface shortwave radiation equal to 


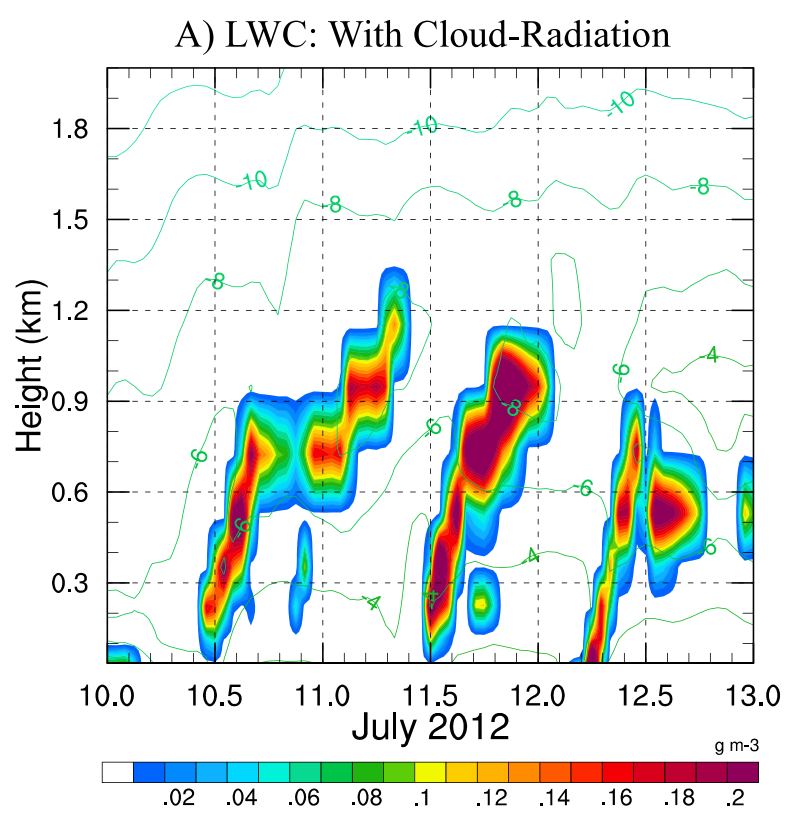

B) LWC: Without Cloud-Radiation

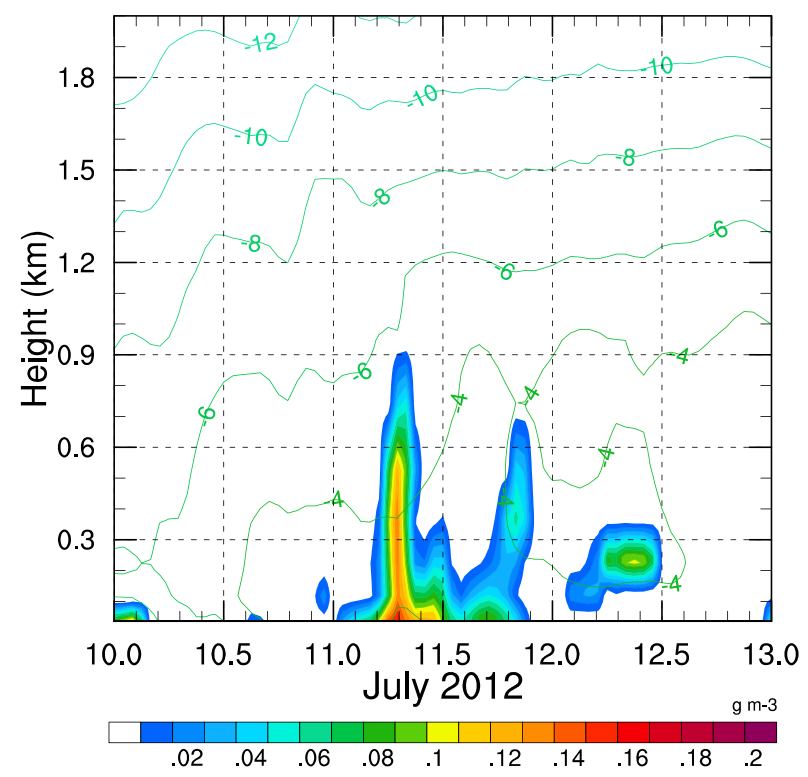

FIG. 7. Impact of cloud radiative fluxes on liquid water content, in units of $\mathrm{g} \mathrm{m}^{-3}$, shown (a) with (control simulation) and (b) without cloud radiative fluxes. The $y$ axis is height from the surface.

$600 \mathrm{~W} \mathrm{~m}^{-2}$ (an approximate value at this time in the presence of thin Arctic mixed-phase clouds) and a surface albedo of 0.9 , this produces an approximate $30 \mathrm{~W} \mathrm{~m}^{-2}$ decrease in upwelling surface shortwave radiation. In the CLM4 land surface model, phase change is a percentage of the conductive ground flux and the terms in the surface energy equation sum to zero. Therefore, all the terms shown in Fig. 10b sum to zero and the impact of the cloud cover is a redistribution of the fluxes among these terms.

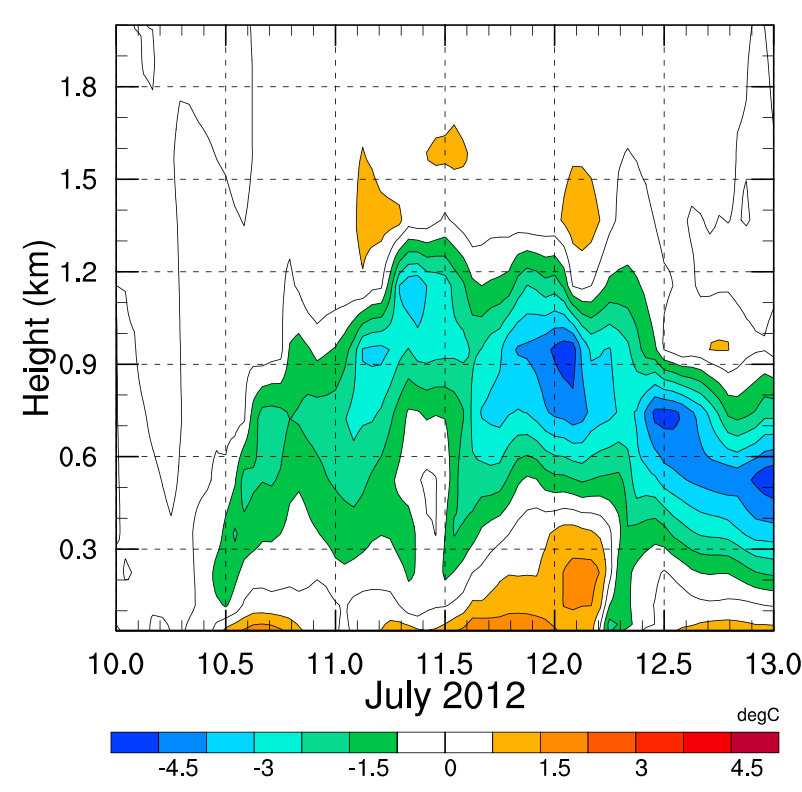

FIG. 8. Temperature difference with and without cloud radiation in the lowest $2 \mathrm{~km}$, in units of ${ }^{\circ} \mathrm{C}$. The $y$ axis is height from the surface.

At times of peak incoming solar radiation, clouds produce an approximate $100 \mathrm{Wm}^{-2}$ in downward longwave, $-20 \mathrm{~W} \mathrm{~m}^{-2}$ in upward longwave, $-40 \mathrm{~W} \mathrm{~m}^{-2}$ in net shortwave, and $-40 \mathrm{Wm}^{-2}$ in conductive + latent + sensible fluxes. Before melt occurs conductive ground fluxes are small and the majority of the $-40 \mathrm{~W} \mathrm{~m}^{-2}$ goes into cooling the surface through turbulent fluxes. After melt begins and the surface temperature is fixed at $0^{\circ} \mathrm{C}$, the majority of the $-40 \mathrm{Wm}^{-2}$ goes into the conductive ground flux, making energy available for further melt. At night, when turbulent heat fluxes are weak, clouds produce approximately $-40 \mathrm{~W} \mathrm{~m}^{-2}$ of conductive ground fluxes. Therefore, conductive ground fluxes are only large when turbulent fluxes are weak (at night and during periods of melt). These results indicate that it is the integrated impact of the clouds over the diurnal cycle that made melt possible (i.e., without the preconditioning of the snowpack by the clouds at night melt would not have occurred the next day).

\section{c. GIS surface energy budget}

In this section we extend the analysis to examine the surface energy fluxes over the whole GIS in the control simulation averaged over 1200-2000 UTC 11 July, the extended period of peak warming in both the model and observations. As is clearly seen in Fig. 11d, the entire GIS experienced melt on 11 July except for the higher elevations of the ice sheet equatorward of Summit and limited areas near the southeast coast. It is notable that this surface melt pattern produced by the regional model is similar to the spatial melt pattern suggested by satellite measurements 


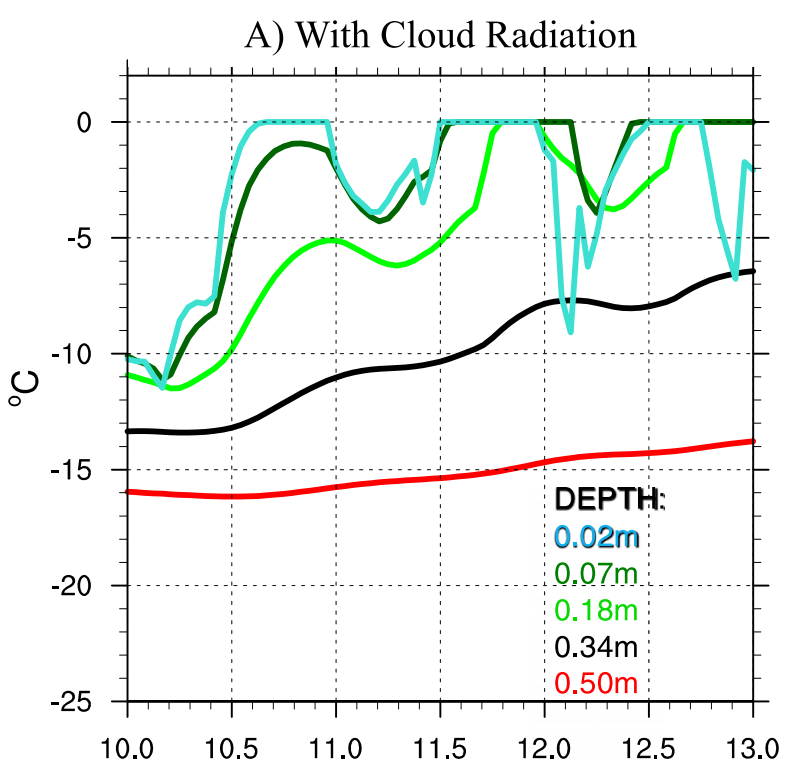

B) Without Cloud Radiation

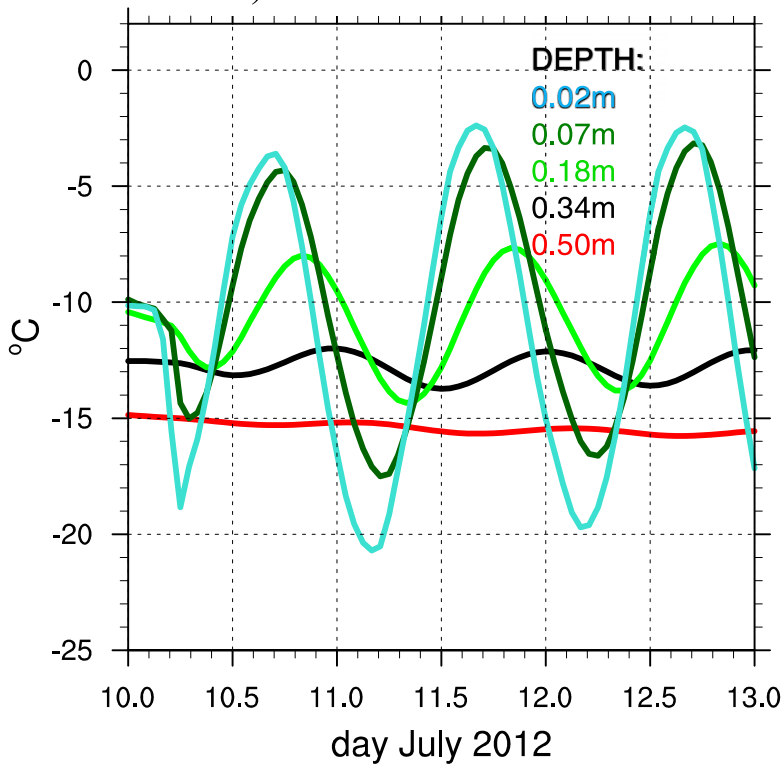

FIG. 9. 10-13 July 2012 surface and subsurface temperatures (a) with and (b) without cloud radiation, in units of $\mathrm{W} \mathrm{m}^{-2}$.

when multiple satellites agreed on the occurrence of melt (Nghiem et al. 2012). Interestingly, the region in southern Greenland that did not experience melt is $\sim 700 \mathrm{~m}$ lower than Summit. Why melt did not occur in the South Dome region is the subject of the next subsection.

Figure 12 shows the surface radiative fluxes for the GIS separated into clear-sky and cloudy (all-sky minus clear-sky) fluxes. Cooling due to cloud shading of shortwave fluxes and warming due to cloud longwave fluxes is seen from the northwest coast to Summit and across the southern tip of Greenland. The thin clouds
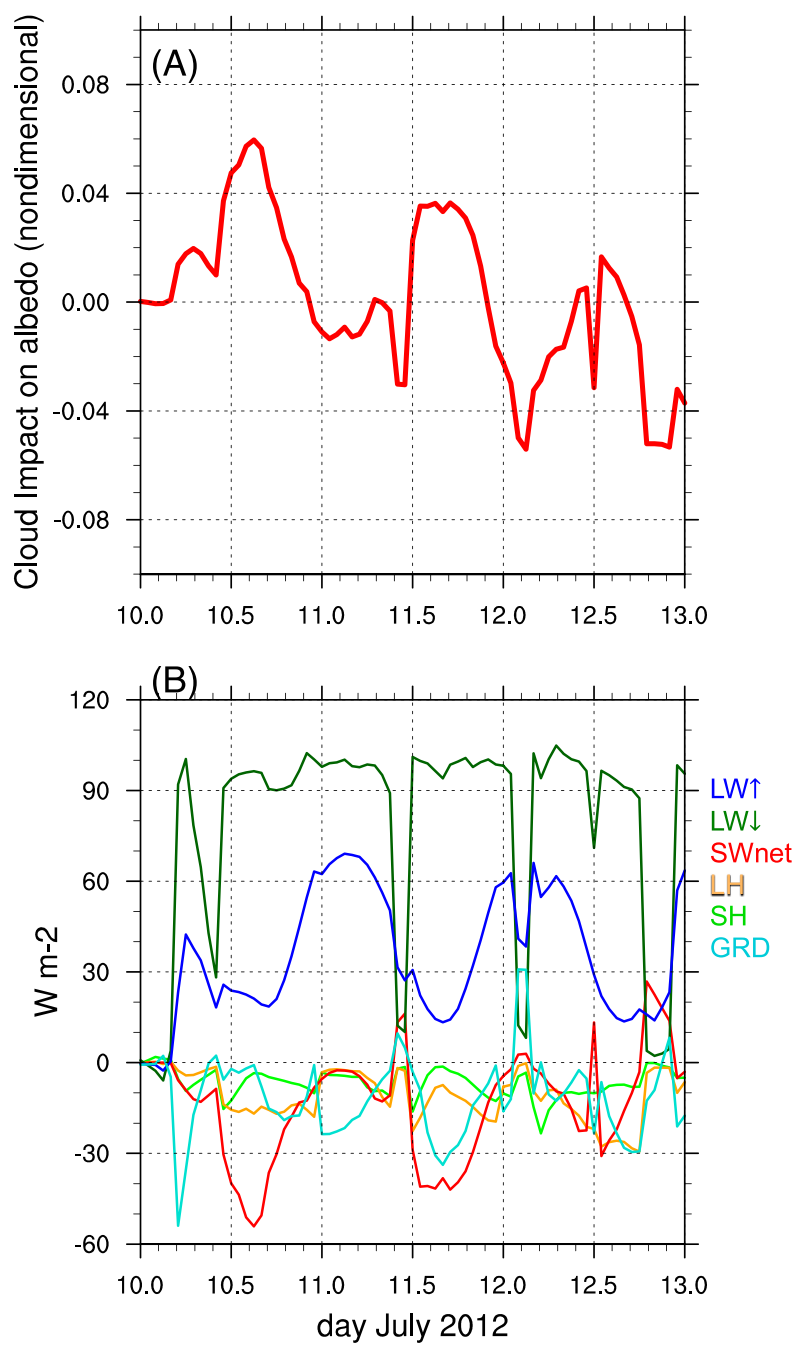

FIG. 10. (a) Surface albedo and (b) surface energy fluxes at Summit 10-13 July 2012 control simulation minus the without cloud radiation "denial" simulation, in units of nondimensional and $\mathrm{W} \mathrm{m}^{-2}$, respectively.

in these regions are opaque in the longwave (Fig. 12b), producing longwave warming of up to $\sim 90 \mathrm{~W} \mathrm{~m}^{-2}$ with generally less shortwave cooling in regions away from the coast $\left(-20\right.$ to $-60 \mathrm{~W} \mathrm{~m}^{-2}$; Fig. 12a). The net radiative flux due to clouds is, thus, a warming for all clouds, independent of LWP, except where albedos are lower than approximately 0.8 (Fig. 11f). Interestingly, cloud radiative fluxes are of the same order as clear-sky radiative fluxes at the higher elevations of the GIS (Fig. 12d), highlighting the importance of these clouds for climate at the top of the GIS and the impact changes in the frequency of occurrence of these cloud systems may have on climate change in this region.

Figure 11 shows the spatial relationship of the total surface energy fluxes due to phase change (Fig. 11d) to 

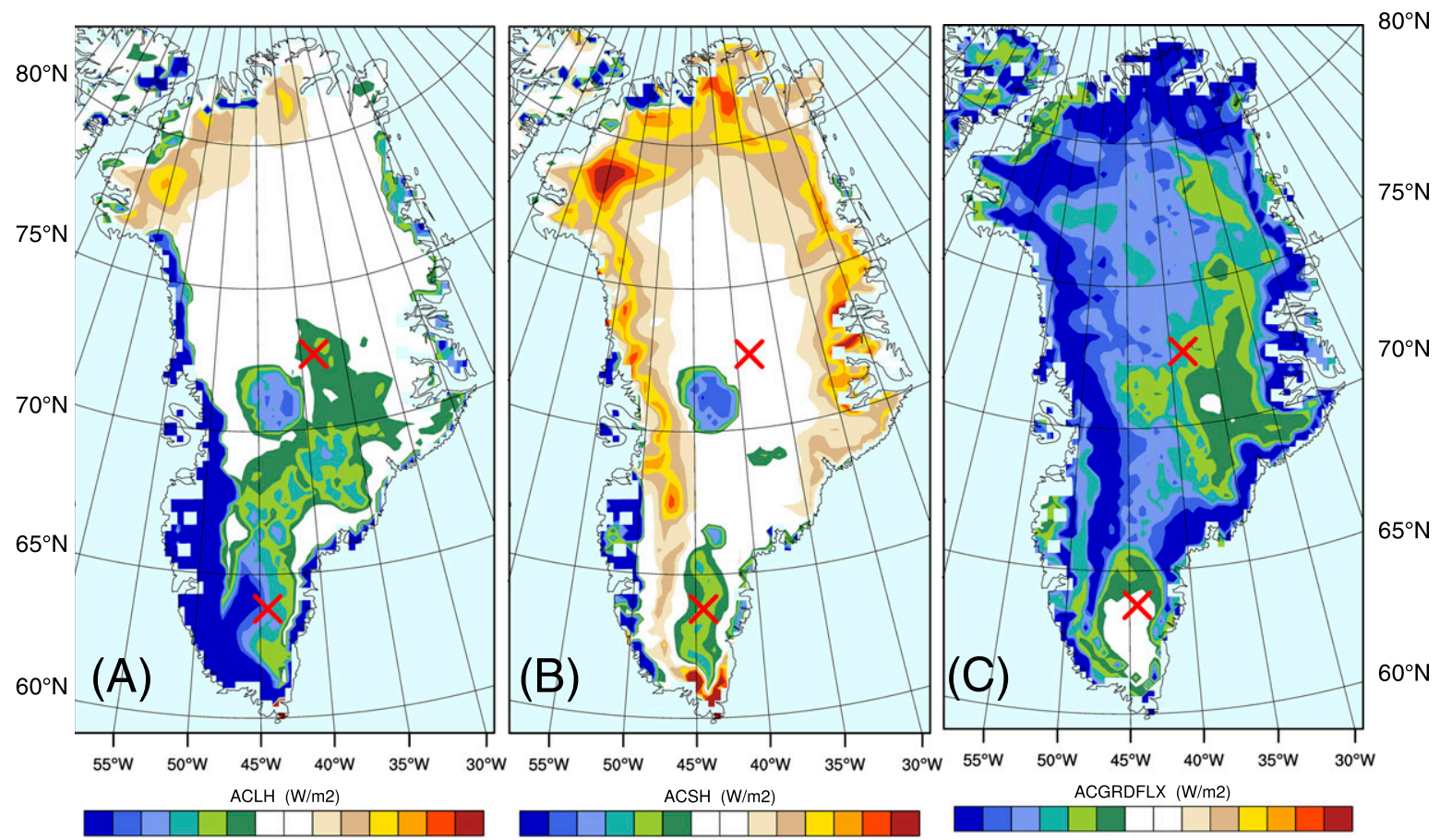

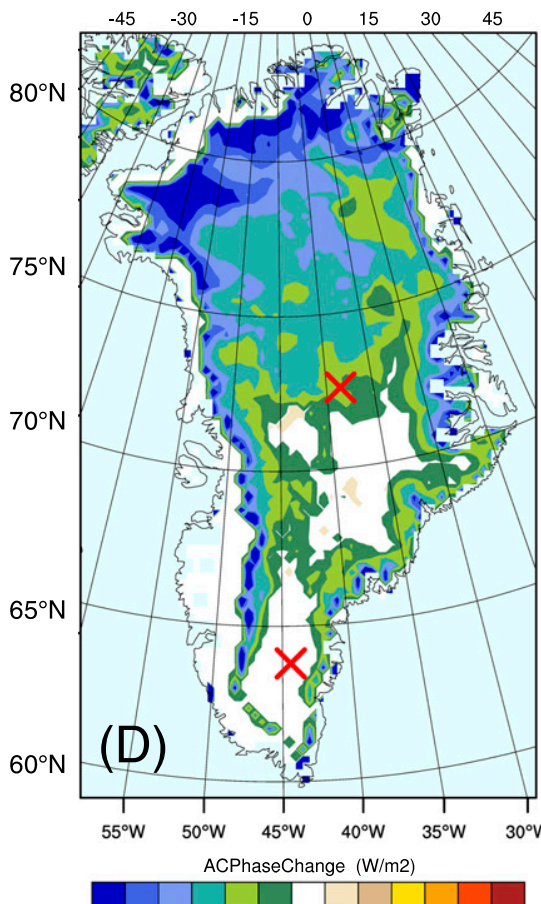

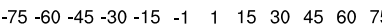

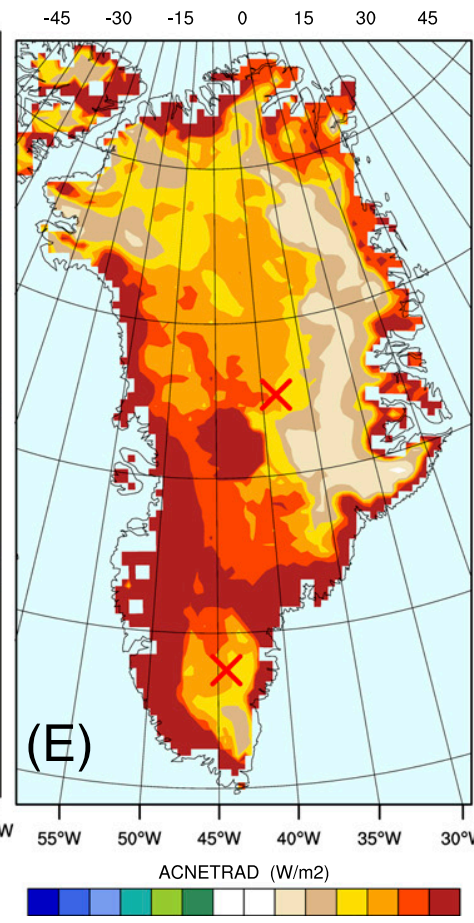

$\begin{array}{lllllll}-90 & -60 & -30 & 0 & 30 & 60 & 90\end{array}$

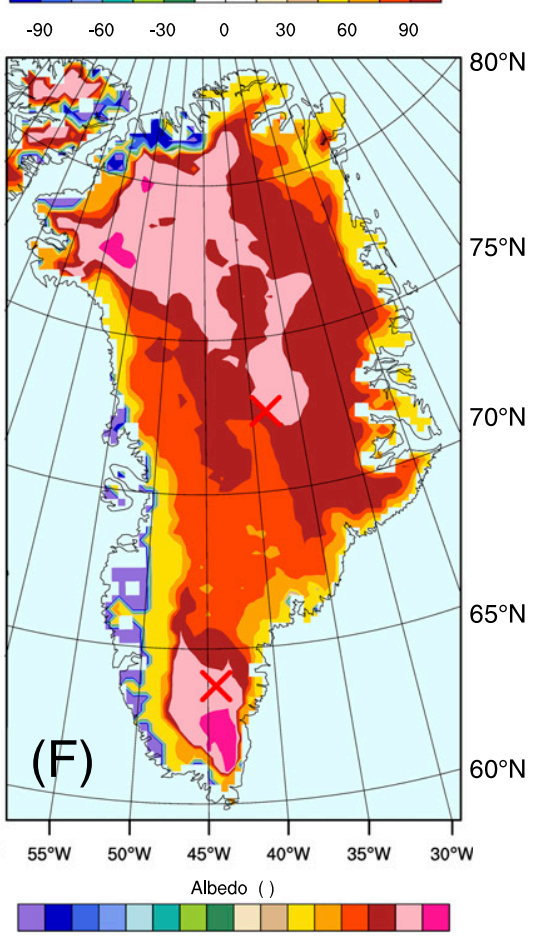

.2 .25 .3 .35 .4 .45 .5 .55 .6 .65 .7 .75 .8 .85 .9

FIG. 11. Surface energy budget terms from 1200 to 2000 UTC $11 \mathrm{Jul} 2012$, in units of $\mathrm{W} \mathrm{m}^{-2}$. (a) Latent heat fluxes. (b) Sensible heat fluxes. (c) Conductive ground fluxes. (d) Energy flux due to phase change. (e) Net radiative fluxes. (f) Average surface albedo. The conductive ground flux $[(\mathrm{c})]$ is equal to $-(\mathrm{a})-(\mathrm{b})-(\mathrm{e})$. The red crosses mark the location of Summit and the top of South Dome.

both turbulent (latent and sensible) and conductive fluxes (Figs. 11a-c) and net radiative fluxes (Fig. 11e). At the top of the GIS, net radiative fluxes only vary from 45 to $60 \mathrm{~W} \mathrm{~m}^{-2}$, balanced by net cooling due to turbulent and conductive fluxes, with the largest surface cooling from these terms occurring from Summit to the south tip of Greenland. This results in more melt to the north of Summit. 

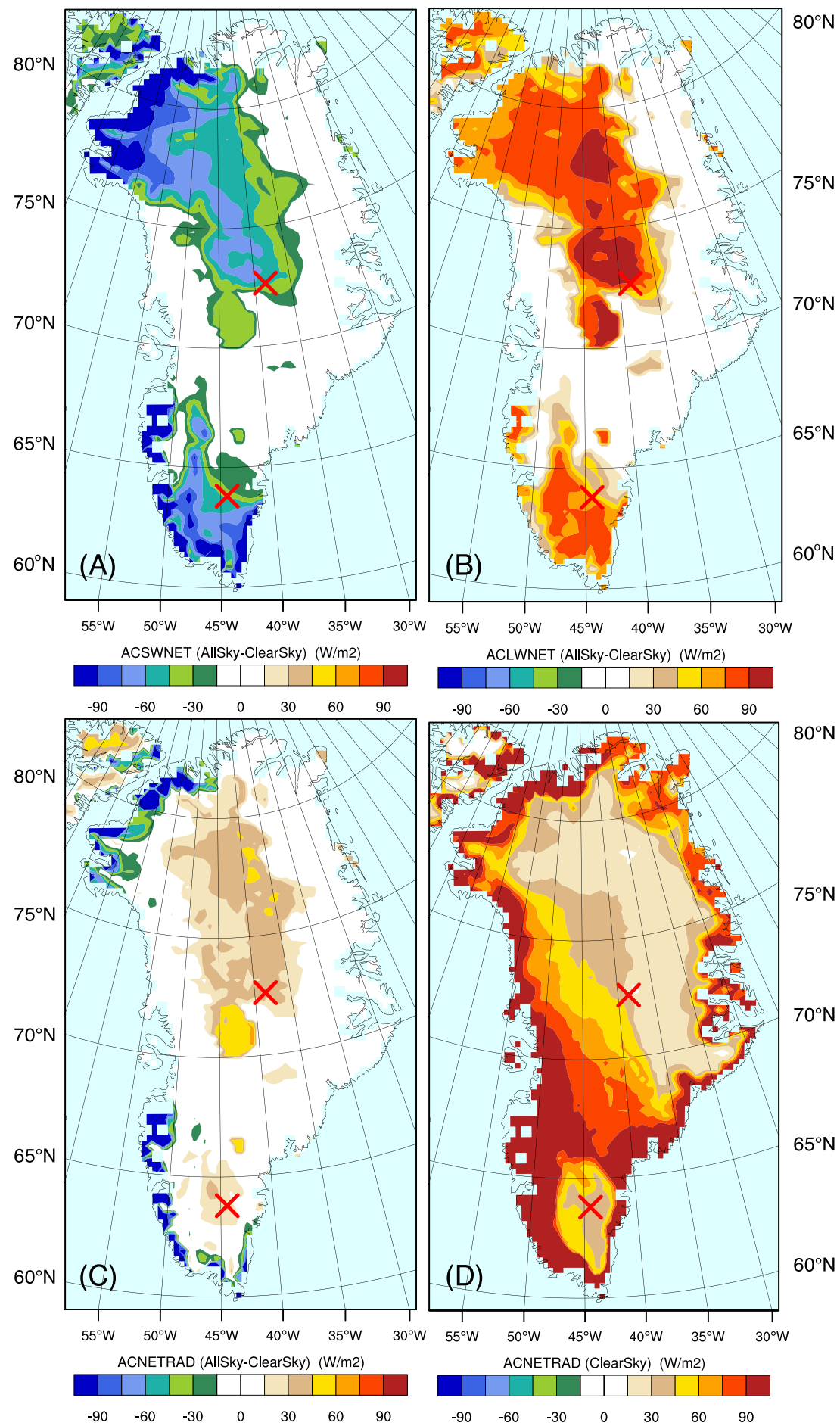

FIG. 12. Net surface radiative fluxes averaged over 1200-2000 UTC 11 Jul 2012, in units of $\mathrm{W} \mathrm{m}^{-2}$, separated into clear-sky and cloudy (all-sky minus clear-sky). (a) Cloud shortwave. (b) Cloud longwave. (c) Net cloud radiation. (d) Net clear-sky radiation. [Note that (a) + (b) equals (c).] The red crosses mark the location of Summit and the top of South Dome. 


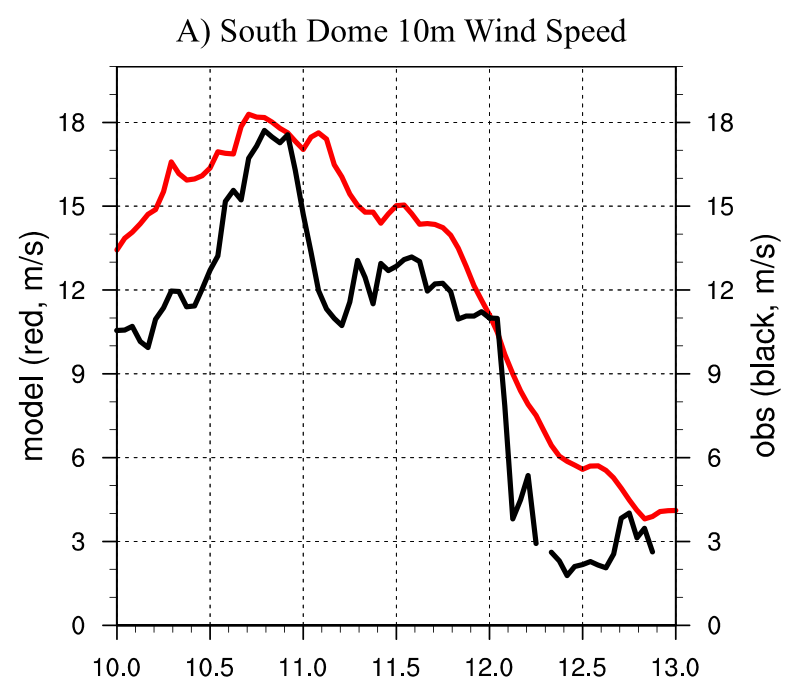

B) South Dome Near-Surface Air Temperature

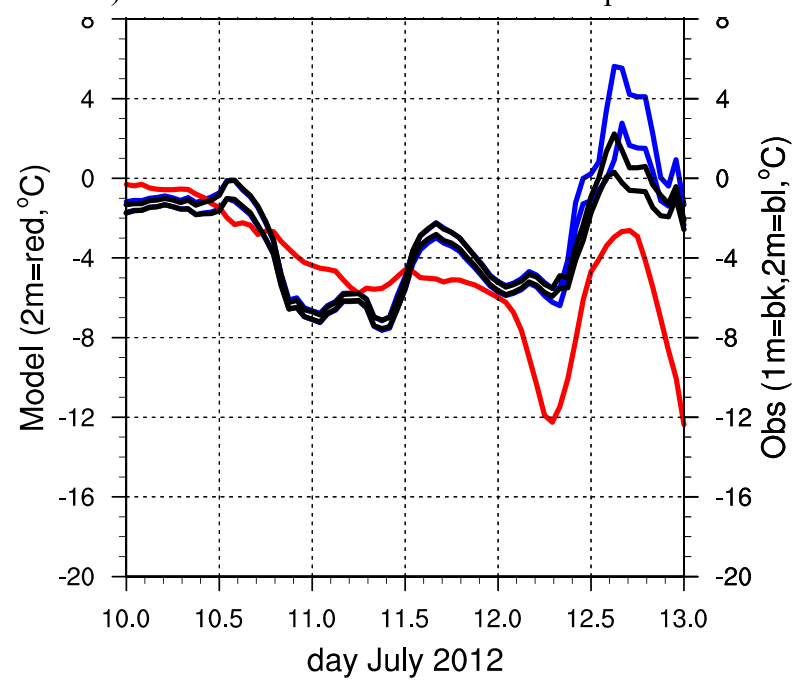

FIG. 13. Comparison of hourly output from control simulation to the Automatic Weather Station measurements (AWS) at South Dome on 10-13 Jul 2012. (a) 10-m wind speed from control simulation (red) and measurements (black), in units of $\mathrm{m} \mathrm{s}^{-1}$. (b) Nearsurface air temperature from control simulation $(2 \mathrm{~m}$; red) and measurements $(1 \mathrm{~m}$, black; $2 \mathrm{~m}$, blue $)$, in units of ${ }^{\circ} \mathrm{C}$.

\section{d. Surface energy balance in the South Dome region}

Figure 11d shows that surface melt did not occur over high elevations south of Summit while the rest of the ice sheet experienced melt. This pattern is interesting considering that the most rapid decrease in ice mass over the 2003-09 period was observed in southern Greenland (e.g., Khan et al. 2010). The area of less than $1 \mathrm{~W} \mathrm{~m}^{-2}$ phase change is consistent with the satellite measurements of "probable melt" on 12 July 2012 (Nghiem et al. 2012) and is consistent with the below $0^{\circ} \mathrm{C}$ temperatures at the South Dome Automatic Weather Station (AWS; Steffen et al. 1996) (Fig. 13). To examine in more detail
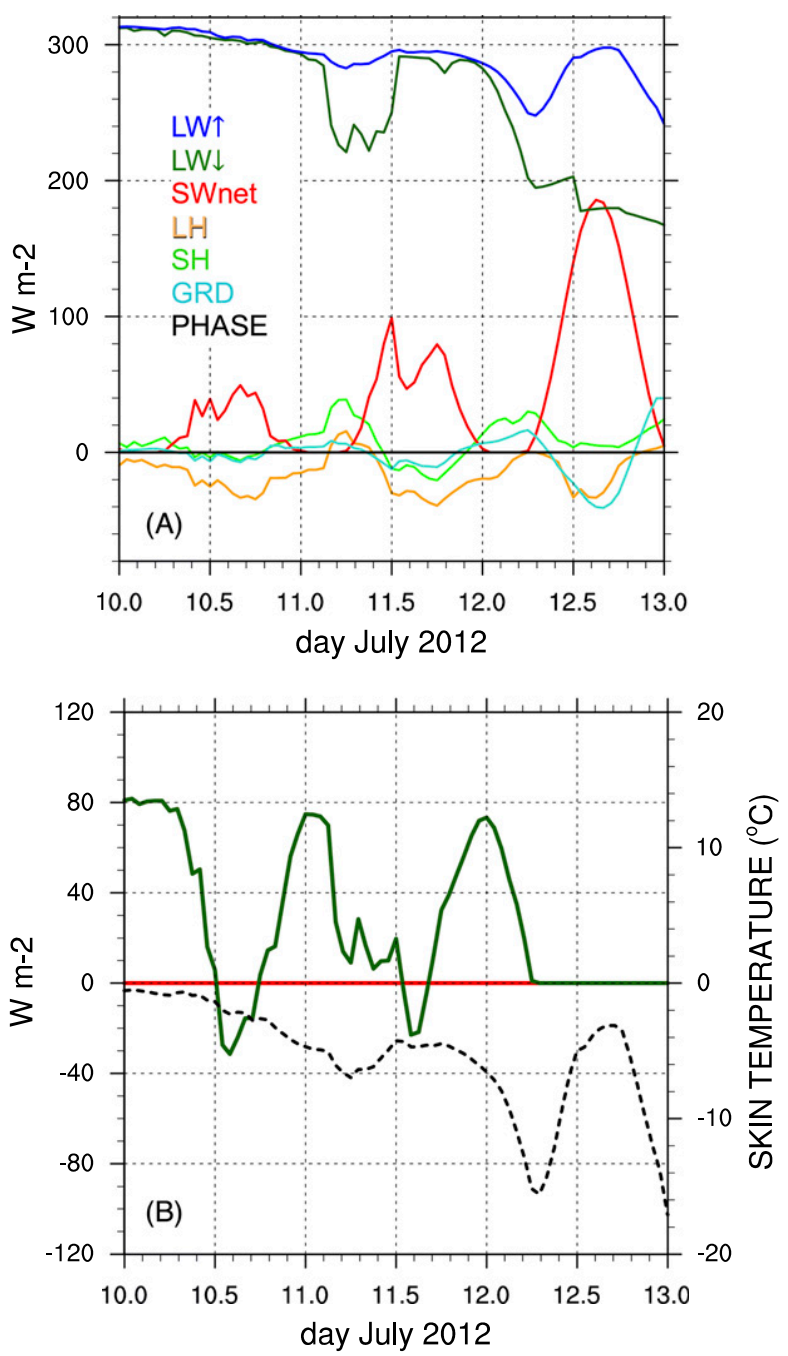

FIG. 14. Simulation of (a) surface energy fluxes (as in Fig. 2b), in units of $\mathrm{W} \mathrm{m}^{-2}$, and (b) cloud radiative fluxes (solid lines) and surface temperature (dashed) at South Dome 10-13 Jul 2012, in units of $\mathrm{W} \mathrm{m}^{-2}$ and ${ }^{\circ} \mathrm{C}$, respectively.

why melt did not occur in this region we focus this section on the variability in the region of South Dome $\left(63.1^{\circ} \mathrm{N}\right.$, $\left.44.8^{\circ} \mathrm{W}\right)$. The model is able to simulate the observed nearsurface air temperature and wind speeds well on 10 and 11 July compared to the AWS measurements (Fig. 13). However, there is an observed diurnal cycle of clear skies during the day and cloudy skies at night that is absent in the model because of homogeneous freezing of cloud liquid at either too moist or too cold air approximately $8 \mathrm{~km}$ above the surface (see the online supplemental material). This causes the modeled near surface temperatures to decrease more rapidly than observed temperatures and temperatures on 12 July to stay below $0^{\circ} \mathrm{C}$.

Figure 14 shows the surface energy budget and cloud radiative fluxes at South Dome from the control 
Init: 2012-07-08 12:00:00

Valid: 2012-07-11 12:00:00

Wind Speed at $10 \mathrm{~m}(\mathrm{~m} / \mathrm{s})$ $\mathrm{U}$ at $10 \mathrm{M} \mathrm{()}$

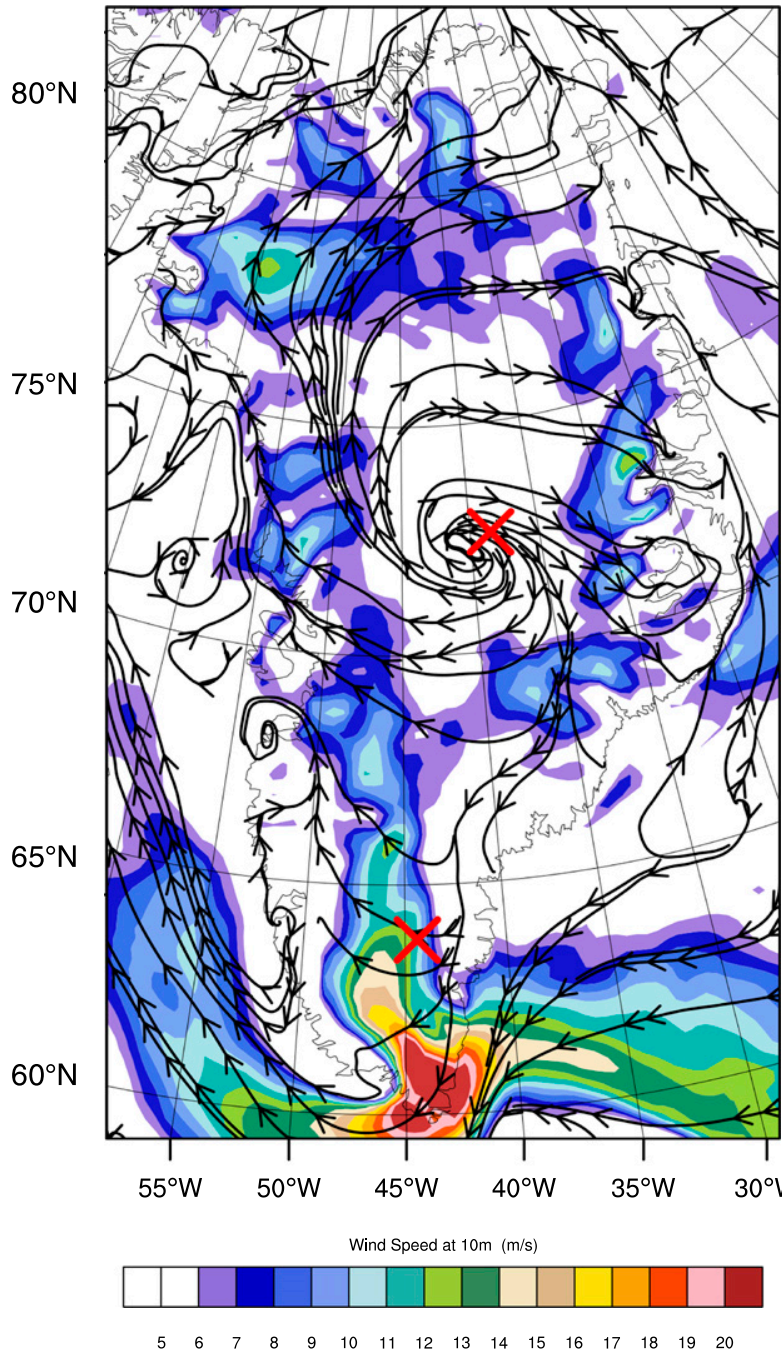

FIG. 15. Simulation of $10-\mathrm{m}$ winds and wind speeds at 1200 UTC $11 \mathrm{Jul} 2012$, in units of $\mathrm{m} \mathrm{s}^{-1}$. The red crosses mark the location of Summit and the top of South Dome.

simulation. Looking at the longwave fluxes first in Fig. 14a, there is an approximate cancellation between the upward and downward surface fluxes in this region. Also, net shortwave fluxes are significantly less than at Summit on 10 July. These differences are due to the large production of cloud ice at higher altitudes, formed through homogeneous freezing where temperatures are less than $-40^{\circ} \mathrm{C}$, which efficiently reflects shortwave radiation back to space.

As a result of larger incoming solar radiation in this region relative to Summit, the balance of cloud shortwave and longwave radiative terms causes the net cloud radiative effect to be negative during times of peak incoming shortwave radiation on 10 and 11 July (Fig. 14b), in contrast to Summit where cloud radiative effect was positive during the entire 3-day period. However, as is seen in Fig. 11, net radiative fluxes in southern Greenland are less than net radiative fluxes at Summit averaged over 1200-2000 UTC 11 July due to enhanced clear-sky radiative fluxes in the south (Fig. 12d). Turbulent fluxes in the region of South Dome (Figs. 11a,b) compensate for the radiative fluxes such that the conductive ground fluxes are negligible (Fig. 11c). This is seen in Fig. 14a, compared to Fig. 2, where the sensible and latent heat fluxes are much larger in magnitude than at Summit.

The large turbulent fluxes in this region are due to anomalously high wind speeds (Fig. 15). These high wind speeds are observed where climatological summertime 10-m wind speeds are less than $7 \mathrm{~m} \mathrm{~s}^{-1}$ (Gorter et al. 2014). At 1200 UTC 11 July 10-m wind speeds at the top of the South Dome exceed $13 \mathrm{~m} \mathrm{~s}^{-1}$ and zonal flow at $10 \mathrm{~m}$ indicates upslope easterly conditions due to the prominent reverse tip jet (Moore 2003) in the region of Cape Farewell with 10-m wind speeds that exceed $25 \mathrm{~m} \mathrm{~s}^{-1}$ (i.e., a gale force event). The WRF simulation shows the winds over South Dome strengthening in time as northerly flow along the eastern edge of the GIS starts to converge with this tip jet feature on 11 July. Reverse tip jets are rarely observed during summer months (Moore 2003), and it is not clear if this feature is related to the synoptic-scale variability that caused this rare melting event over Greenland.

\section{Summary and discussion}

In this study we used limited-area model simulations of the 10-13 July 2012 extreme Greenland Ice Sheet melt event to investigate both cloud radiative effect estimates and the response of coupled feedbacks due to the formation of low-level clouds that influence surface energy fluxes, and therefore the energy available for melt. First, considering the central GIS around Summit, these simulations showed that $\sim 95 \%$ of the air mass that formed mixed-phase clouds in this region during the extreme melt event was advected into the domain from the southern boundary $\left(\sim 58^{\circ} \mathrm{N}\right)$ above the boundary layer. This is in general agreement with large-scale analyses at the time (e.g., Neff et al. 2014). Both the model and measurements showed that surface temperatures were at $0^{\circ} \mathrm{C}$ for extended periods on 10 July and 11 July at Summit. The model was able to well represent radiative and turbulent heat flux observations when available as well as the temporal evolution of surface albedo. The model also produced reasonable cloud LWP and 
IWP magnitudes and variability over the 3-day period. During these days, the amount of energy that went into surface melt exceeded $20 \mathrm{~W} \mathrm{~m}^{-2}$ on 10 July and $30 \mathrm{~W} \mathrm{~m}^{-2}$ on 11 July.

This study demonstrates that cloud radiative effect at Summit was always positive, even during maximum incoming solar radiation [similar to the observational study of Miller et al. (2015)]. A model control simulation showed that there was a short period on 11 July when the solar radiation was strong enough to produce melt without the instantaneous radiative effects of clouds; however, the extensive melt over the 3-day period was only possible due to the presence of liquid-bearing clouds, in agreement with Bennartz et al. (2013). This was further confirmed by a sensitivity study that showed that removing the cloud radiative effects resulted in no melt during this time, even though fluxes in the control simulation indicated melt would have occurred at the peak of 11 July without clouds. This is a result of how the net surface response to clouds extends beyond instantaneous radiative effects to include feedbacks and responses in the system. When clouds are present, they reduce stratification from cloud top to the surface through a combination of radiative heating of the surface, cloud-top radiative cooling, and cloud-driven turbulent mixing, which homogenizes the cloud-topped boundary layer.

The cloud radiation denial experiment was designed so that local cloud feedbacks are modified while remote forcing by the advected air mass is unchanged. Cloud impacts beyond the cloud radiative effect were identified by the difference between the control simulation and the sensitivity experiment. It was found that Arctic mixed-phase stratocumuli were not produced in the sensitivity experiment, highlighting that the cloud radiative fluxes are required to maintain the clouds. A number of feedbacks were found to damp the warming effect of the clouds. First, clouds increase the surface albedo by $0.04-0.06$, resulting in an approximate increase of $30 \mathrm{~W} \mathrm{~m}^{-2}$ in upward surface shortwave radiation during time of peak incoming solar radiation. Second, clouds decrease the sum of turbulent + conductive ground fluxes by approximately $-40 \mathrm{~W} \mathrm{~m}^{-2}$. It is only at times of weak turbulent fluxes (i.e., at night or during melt) that this energy goes into the conductive ground flux, providing energy for melt. From these results we conclude that it is the integrated impact of the clouds over the diurnal cycle (the preconditioning of the snowpack by the clouds at night) that made melt possible during this 3-day period.

With this understanding of the cloud-atmospheresurface system at Summit, model results were used to expand this understanding beyond Summit to the full
GIS during the peak of the melt event at 1200-2000 UTC 11 July. Generally across Greenland, the net radiative effect of clouds was a warming for all clouds, independent of LWP, except where albedo was lower than approximately 0.8 . However, this was not the case in southern Greenland where the cooling effect due to a reflection of shortwave radiation dominated over the warming due to an increase in downward longwave radiation. Conductive heat fluxes were weakly negative across the ice sheet as subsurface temperatures slowly warmed, which in turn diminished the conductive fluxes themselves. Over the ice sheet, turbulent sensible and latent heat fluxes generally decreased from north to south, with weak positive net turbulent fluxes around much of the Greenland coast. Although over Summit the turbulent heat fluxes were largely a response to the net surface radiative heat fluxes (i.e., driven by surface temperature changes), the same response did not characterize regions to the south of Summit. Net surface turbulent heat fluxes produced strong cooling at the surface in the South Dome region due to anomalously high winds in this area related to a reverse tip jet along the southern tip of Greenland. The resulting strongly negative turbulent heat fluxes more than counteracted the relatively weak net radiative warming in this region such that melt did not occur.

This study has demonstrated the strength of using models and observations synergistically to understand key drivers of GIS surface energy budgets and melt. Using the July 2012 extreme melt event, the model was able to well represent the observed temporal variability of clouds, surface energy fluxes, and melt at Summit as well as the spatial distribution of melt across the GIS. The model simulations then offered the ability to expand process understanding beyond Summit and beyond the instantaneous radiative effects of clouds. Results showed that low-level liquid-bearing clouds were important over the central GIS both for their direct radiative effects and for the responses they elicited within the system. These impacts highlight the importance of clouds for influencing the climate of the GIS. In addition, model results indicated that large-scale features, such as the reverse tip jet, can also play a significant role in modulating cloud effects and impacting surface melt. To understand and model GIS melt processes into the future will require adequate representation of large-scale circulation, clouds, surface energy fluxes, and their interactions.

Acknowledgments. This research was supported by the National Science Foundation (PLR-1314156). Cloud and atmosphere observations were obtained from the NSF ICECAPS project (PLR-1303879, 1414314, 1304544, 
1304692). David Noone (NSF PLR-1023574) provided measurements of surface sensible heat flux, as computed by Christopher Cox. Konrad Steffen (Swiss Federal Institute of Technology) provided surface radiative flux measurements. Model forcing data sets were obtained from the European Centre for Medium-Range Weather Forecasts. We thank the numerous scientists and technicians responsible for obtaining and producing all observations. We thank three anonymous reviewers and the editor for constructive comments that helped to improve this manuscript.

\section{REFERENCES}

Abdul-Razzak, H., and S. J. Ghan, 2000: A parameterization of aerosol activation: 2. Multiple aerosol types. J. Geophys. Res., 105, 6837-6844, doi:10.1029/1999JD901161.

Bennartz, R., and Coauthors, 2013: July 2012 Greenland melt extent enhanced by low-level liquid clouds. Nature, 496, 83-86, doi:10.1038/nature12002.

Bergeron, T., 1935: On the physics of cloud and precipitation. Proc. 5th Assembly U.G.G.I., Vol. 2, International Union of Geodesy and Geophysics, Lisbon, Portugal, 156-178.

Bretherton, C. S., J. R. McCaa, and H. Grenier, 2004: A new parameterization for shallow cumulus convection and its application to marine subtropical cloud-topped boundary layers. Part I: Description and 1-D results. Mon. Wea. Rev., 132, 864 882, doi:10.1175/1520-0493(2004)132<0864:ANPFSC $>2.0 . C O ; 2$.

Collins, W. D., P. J. Rasch, B. A. Boville, J. J. Hack, J. R. McCaa, D. L. Williamson, and B. P. Briegleb, 2004: Description of the NCAR Community Atmosphere Model (CAM 3.0). NCAR Tech. Note NCAR/TN-464+STR, 226 pp.

Fettweis, X., B. Franco, M. Tedesco, J. H. van Angelen, J. T. M. Lenaerts, M. R. van den Broeke, and H. Gallée, 2013: Estimating the Greenland ice sheet surface mass balance contribution to future sea level rise using the regional atmospheric climate model MAR. Cryosphere, 7, 469-489, doi:10.5194/ tc-7-469-2013.

Findeisen, W., 1938: Die kolloidmeteorologischen Vorgänge bei der Niederschlagsbildung (Colloidal meteorological processes in the formation of precipitation). Meteor. Z., 55, 121-133.

Flanner, M. G., and C. S. Zender, 2005: Snowpack radiative heating: Influence on Tibetan Plateau climate. Geophys. Res. Lett., 32, L06501, doi:10.1029/2004GL022076.

_ evolution. J. Geophys. Res., 111, D12208, doi:10.1029/ 2005JD006834.

Gorter, W., J. H. van Angelen, J. T. M. Lenaerts, and M. R. van den Broeke, 2014: Present and future near-surface wind climate of Greenland from high resolution regional climate modelling. Climate Dyn., 42, 1595-1611, doi:10.1007/s00382-013-1861-2.

Grenier, H., and C. S. Bretherton, 2001: A moist PBL parameterization for large-scale models and its application to subtropical cloud-topped marine boundary layers. Mon Wea. Rev., 129, 357-377, doi:10.1175/1520-0493(2001)129<0357. AMPPFL $>2.0 . \mathrm{CO} ; 2$

Hanna, E., J. Cappelen, X. Fettweis, S. Mernild, T. Mote, K. Steffen, and L. Wood, 2013: Atmospheric and oceanic climatic forcing of the exceptional Greenland ice sheet surface melt in summer 2012. Int. J. Climatol., 34, 1022-1037, doi:10.1002/ joc.3743.
_, and Coauthors, 2014: Atmospheric and oceanic climate forcing of the exceptional Greenland ice sheet surface melt in summer 2012. Int. J. Climatol., 34, 1022-1037, doi:10.1002/joc.3743.

IPCC, 2013: Climate Change 2013: The Physical Science Basis. T. F. Stocker et al. Eds., Cambridge University Press, 1535 pp., doi:10.1017/CBO9781107415324.

Jacob, T., J. Wahr, W. T. Pfeffer, and S. Swenson, 2012: Recent contributions of glaciers and ice caps to sea level rise. Nature, 482, 514-518, doi:10.1038/nature10847.

Jiménez, P. A., J. Dudhia, J. F. González-Rouco, J. Navarro, J. P. Montávez, and E. García-Bustamante, 2012: A revised scheme for the WRF surface layer formulation. Mon. Wea. Rev., 140, 898-918, doi:10.1175/MWR-D-11-00056.1.

Khan, S. A., J. Wahr, M. Bevis, I. Velicogna, and E. Kendrick, 2010: The spread of ice mass loss into northwest Greenland observed by GRACE and GPS. Geophys. Res. Lett., 37, L06501, doi:10.1029/2010GL042460.

Lawrence, D. M., and Coauthors, 2011: Parameterization improvements and functional and structural advances in version 4 of the Community Land Model. J. Adv. Model. Earth Syst., 3, M03001, doi:10.1029/2011MS00045.

Maier-Reimer, E., and U. Mikolajewicz, 1989: Experiments with an OGCM on the cause of the Younger Dryas. Oceanography 1988, A. Ayala-Castanares, W. Wooster, and A. YanezAranciba, Eds., UNAM Press, 87-100.

Miller, N. B., M. D. Shupe, C. J. Cox, V. P. Walden, D. D. Turner, and K. Steffen, 2015: Cloud radiative forcing at Summit, Greenland. J. Climate, 28, 6267-6280, doi:10.1175/JCLI-D-15-0076.1.

Moore, G. W. K., 2003: Gale force winds over the Irminger Sea to the east of Cape Farewell, Greenland. Geophys. Res. Lett., 30, 1894, doi:10.1029/2003GL018012.

Morrison, H., and J. O. Pinto, 2005: Mesoscale modeling of springtime Arctic mixed- phase stratiform clouds using a new two-moment bulk microphysics scheme. J. Atmos. Sci., 62, 3683-3704, doi:10.1175/JAS3564.1.

, G. Thompson, and V. Tatarskii, 2009: Impact of cloud microphysics on the development of trailing stratiform precipitation in a simulated squall line: Comparison of one- and two-moment schemes. Mon. Wea. Rev., 137, 991-1007, doi:10.1175/2008MWR2556.1.

— , G. de Boer, G. Feingold, J. Harrington, M. D. Shupe, and K. Sulia, 2012: Resilience of persistent Arctic mixed-phase clouds. Nat. Geosci., 5, 11-17, doi:10.1038/ngeo1332.

Neff, W., G. Compo, F. M. Ralph, and M. D. Shupe, 2014: Continental heat anomalies and the extreme melting of the Greenland ice surface in 2013 and 1889. J. Geophys. Res., 119, 6520-6536, doi:10.1002/2014JD021470.

Nghiem, S. V., and Coauthors, 2012: The extreme melt across the Greenland Ice Sheet in 2012. Geophys. Res. Lett., 39, L20502, doi:10.1029/2012GL053611.

Nicholls, R. J., and A. Cazenave, 2010: Sea-level rise and its impact on coastal zones. Science, 328, 1517-1520, doi:10.1126/ science. 1185782.

Oleson, K. W., and Coauthors, 2010: Technical description of version 4.0 of the Community Land Model (CLM). NCAR Tech. Note NCAR/TN-478+STR, 257 pp.

Overland, J. E., J. A. Francis, E. Hanna, and M. Wang, 2012: The recent shift in early summer Arctic atmospheric circulation. Geophys. Res. Lett., 39, L19804, doi:10.1029/2012GL053268.

Rahmstorf, S., J. Box, G. Feulner, M. Mann, A. Robinson, S. Rutherford, and E. Schaffernicht, 2015: Exceptional twentiethcentury slowdown in Atlantic Ocean overturning circulation. Nat. Climate Change, 5, 475-480, doi:10.1038/nclimate2554. 
Ridley, J., J. Gregory, P. Huybrechts, and J. Lowe, 2010: Thresholds for irreversible decline of the Greenland ice sheet. Climate Dyn., 35, 1049-1057, doi:10.1007/s00382-009-0646-0.

Rignot, E., I. Velicogna, M. R. van den Broeke, A. Monaghan, and J. Lenaerts, 2011: Acceleration of the contribution of the Greenland and Antarctic ice sheets to sea level rise. Geophys. Res. Lett., 38, L05503, doi:10.1029/2011GL046583.

Shupe, M. D., and J. M. Intrieri, 2004: Cloud radiative forcing of the Arctic surface: The influence of cloud properties, surface albedo, and solar zenith angle. J. Climate, 17, 616-628, doi:10.1175/1520-0442(2004)017<0616:CRFOTA >2.0.CO;2.

— , and Coauthors, 2013: High and dry: New observations of tropospheric and cloud properties above the Greenland Ice Sheet. Bull. Amer. Meteor. Soc., 94, 169-186, doi:10.1175/ BAMS-D-11-00249.1.

_ D. D. Turner, A. Zwink, M. M. Theiman, J. J. Mlawer, and T. R. Shippert, 2015: Deriving Arctic cloud microphysics at Barrow: Algorithms, results, and radiative closure. J. Appl. Meteor. Climatol., 54, 1675-1689, doi:10.1175/JAMC-D-15-0054.1.

Skamarock, W. C., and Coauthors, 2008: A description of the Advanced Research WRF version 3. NCAR Tech. Note NCAR/TN-475+STR, 113 pp. [Available online at http:// www.mmm.ucar.edu/wrf/users/docs/arw_v3.pdf.]

Steffen, K., J. E. Box, and W. Abdalati, 1996: Greenland Climate Network: GC-Net. CRREL 96-27 Special Rep. on Glaciers, Ice Sheets and Volcanoes, S. C. Colbeck, Ed., 98-103.

Stouffer, R. J., and Coauthors, 2006: Investigating the causes of the response of the thermohaline circulation to past and future climate changes. J. Climate, 19, 1365-1387, doi:10.1175/JCLI3689.1.

Strellis, B., 2013: Aerosol forcing over central Greenland: Estimates based on field measurements. M.S. thesis, School of
Environmental Engineering, Georgia Institute of Technology, 70 pp. [Available online at https://smartech.gatech.edu/ bitstream/handle/1853/49063/STRELLIS-THESIS-2013.pdf.]

Tedesco, M., and Coauthors, 2013: [Arctic] Greenland ice sheet [in "State of the Climate in 2012"]. Bull. Amer. Meteor. Soc., 94, S121-S123.

Toon, O. B., C. P. Mckay, T. P. Ackerman, and K. Santhanam, 1989: Rapid calculation of radiative heating rates and photodissociation rates in inhomogeneous multiple-scattering atmospheres. J. Geophys. Res., 94, 16 287-16301, doi:10.1029/ JD094iD13p16287.

Turner, D. D., and Coauthors, 2007a: Thin liquid water clouds: Their importance and our challenge. Bull. Amer. Meteor. Soc., 88, 177-190, doi:10.1175/BAMS-88-2-177.

- S. A. Clough, J. C. Liljegren, E. E. Clothiaux, K. E. Cady-Pereira, and K. L. Gaustad, 2007b: Retrieving liquid water path and precipitable water vapor from the Atmospheric Radiation Measurement (ARM) microwave radiometers. IEEE Trans. Geosci. Remote Sens., 45, 3680-3690, doi:10.1109/TGRS.2007.903703.

Vaughan, D. G., and Coauthors, 2013: Observations: Cryosphere. Climate Change 2013: The Physical Science Basis, T. F. Stocker et al., Eds., Cambridge University Press, 317-382.

Wegener, A., 1911: Thermodynamik der Atmosphäre. Barth, $331 \mathrm{pp}$.

Yin, J., M. E. Schlesinger, and R. J. Stouffer, 2009: Model projections of rapid sea-level rise on the northeast coast of the United States. Nat. Geosci., 2, 262-266, doi:10.1038/ngeo462.

Zwally, H. J., W. Abdalati, T. Herring, K. Larson, J. Saba, and K. Steffen, 2002: Surface melt-induced acceleration of Greenland ice-sheet flow. Science, 297, 218-222, doi:10.1126/ science.1072708. 